\title{
Updates on enzymatic and structural properties of human glutamine: fructose-6-phosphate amidotransferase 2 (hGFAT2)
}

Isadora A. Oliveira ${ }^{1 *}$, Diego Allonso ${ }^{1,2}$, Tácio V. A. Fernandes ${ }^{3,4}$, Daniela M. S. Lucena ${ }^{1}$, Gustavo T. Ventura $^{1}$, Wagner B. Dias ${ }^{1}$, Ronaldo S. Mohana-Borges ${ }^{5}$, Pedro G. Pascutti ${ }^{3}$, Adriane R. Todeschini ${ }^{1 *}$.

${ }^{1}$ Laboratório de Glicobiologia Estrutural e Funcional, Instituto de Biofísica Carlos Chagas Filho (IBCCF), Universidade Federal do Rio de Janeiro (UFRJ); ${ }^{2}$ Departamento de Biotecnologia Farmacêutica, Faculdade de Farmácia, UFRJ; ${ }^{3}$ Laboratório de Modelagem e Dinâmica Molecular, IBCCF, UFRJ; ${ }^{4}$ Laboratório de Macromoléculas, Diretoria de Metrologia Aplicada às Ciências da Vida, Instituto Nacional de Metrologia, Qualidade e Tecnologia (INMETRO), Duque de Caxias, RJ 25250-020, Brazil; ${ }^{5}$ Laboratório de Genômica Estrutural, IBCCF, UFRJ, Rio de Janeiro, RJ 21941-902, Brazil.

* Corresponding authors: Adriane R. Todeschini and Isadora Oliveira.

E-mails: adrianet@biof.ufrj.br, isadora@biof.ufrj.br

Running title: Insights into enzymatic properties of hGFAT2

Present address: Isadora A. Oliveira, Centro de Espectrometria de Massas de Biomoléculas (CEMBIO), UFRJ, Brazil.

Keywords: Glutamine:fructose-6-phosphate amidotransferase (GFAT), glucosamine-6-phosphate synthase, hexosamine biosynthetic pathway (HBP), carbohydrate metabolism, enzyme kinetics, protein structure, molecular modelling, molecular dynamics. 


\section{Abstract}

Glycoconjugates play a central role in several cellular processes and alteration in their composition is associated to human pathologies. The hexosamine biosynthetic pathway is a route through which cells obtain substrates for cellular glycosylation, and is controlled by the glutamine: fructose-6-phosphate amidotransferase (GFAT). Human isoform 2 GFAT (hGFAT2) has been implicated in diabetes and cancer, however, there is no information about structural and enzymatic properties of this enzyme. Here, we report a successful expression and purification of a catalytically active recombinant hGFAT2 (rhGFAT2) in E. coli cells fused or not to a HisTag at the C-terminal end. Our enzyme kinetics data suggest that hGFAT2 does not follow the ordered bi-bi mechanism, and performs the glucosamine-6-phosphate synthesis much slowly than previously reported for other GFATs. In addition, hGFAT2 is able to isomerase fructose-6-phosphate into glucose-6-phosphate even in presence of equimolar amounts of glutamine, in an unproductive glutamine hydrolysis. Structural analysis of the generated three-dimensional model rhGFAT2, corroborated by circular dichroism data, indicated the presence of a partially structured loop in glutaminase domain, whose sequence is present in eukaryotic enzymes but absent in the E. coli homolog. Molecular dynamics simulations show such loop as the most flexible portion of the protein, which interacts with the protein mainly through the interdomain region, and plays a key role on conformational states of hGFAT2. Altogether, our study provides the first comprehensive set of data on the structure, kinetics and mechanics of hGFAT2, which will certainly contribute for further studies focusing on drug development targeting hGFAT2.

\section{Introduction}

Glycoconjugates are particularly diverse in structure and composition and play a central role in several cellular processes such as cell growth, cell-cell and cell-matrix adhesion, cell differentiation among others. Severe alterations in the composition of glycoconjugates are usually associated to human diseases $(1,2)$. The primary substrates for intra- and extracellular glycosylation are obtained through the hexosamine biosynthetic pathway (HBP), which is controlled by the rate-limiting enzyme glutamine:fructose-6-phosphate amidotransferase (GFAT) (3).

The enzyme GFAT belongs to the amidotransferase family, class II, characterized by an N-terminal cysteine as the nucleophilic catalyst (4). All cellular organisms including prokaryotes and eukaryotes express this class of enzymes, highlighting their relevance to normal cell functioning. Indeed, deletion of the GFAT gene in Escherichia coli and Saccharomyces pombe led to cell death (5). In mammals, GFAT was characterized in 1960 in rat liver homogenates, when Ghosh et al. (6) described its specificity for fructose-6-phosphate (Fru-6P) and not glucose-6-phosphate (Glc-6P) for glucosamine-6-phosphate $(\mathrm{GlcN}-6 \mathrm{P})$ generation. In humans, three different isoforms of GFAT were reported, named hGFAT1, hGFAT1Alt (or GFAT1-L) and hGFAT2, encoded by the gfpt1 and gfpt2 genes, respectively. hGFAT1 expression is ubiquitous and it is highly expressed in placenta, pancreas and testis (7). hGFAT1Alt represents an expanded isoform of hGFAT1 resulting from alternative splicing of the $g f p t 1$ gene, and its expression is restricted to striated muscle $(8,9)$. In turn, hGFAT2 is the product of a distinct gene, $g f p t 2$, and shares $79 \%$ identity with hGFAT1 (7). hGFAT2 presents a more restricted expression pattern than hGFAT1, being the major isoform in several central nervous system tissues and observed in a smaller proportion in the heart, placenta, testis and ovary (7).

Interest in hGFAT has increased in the past few years as this protein has been implicated in human pathologies. The hGFATs play a direct role in type 2 diabetes and their overexpression contributes to insulin resistance and higher $O$ GlcNAc levels (10-12). In fact, previous work has identified hGFATs as potential targets for the development of anti-diabetes drugs $(12,13)$. In addition to diabetes, hGFAT has been assigned a prominent role in the close relationship between HBP and cancer. hGFAT1 isoform has been observed to be up-regulated in breast (14), prostate (15) and hepatic (16) cancers. On the other hand, it has been observed that hGFAT2 levels increased considerably in pancreatic adenocarcinoma (17) and colorectal cancer (18). 
Despite its importance in cellular metabolism, there is few works uncovering biochemical and kinetics properties of mammalian GFATs. The structure of GFAT is characterized by having two domains, glutaminase (GLN) and isomerase (ISOM), responsible for its enzymatic activity. The complete reaction mechanism of GFAT was proposed from studies with GlcN-6P synthase (GlmS), the bacterial homolog of hGFAT, being characterized as bi-bi-ordered in which the entry of Fru-6P induces conformational changes that favor glutamine (Gln) binding (19). Concerning the hGFATs, most studies to date have focused on unraveling the mechanisms and structure of isoform 1 (20-22). This isoform naturally occurs as a homotetramer, which is its active oligomeric state $(21,23)$. In contrast to $E$. coli $\mathrm{GlmS}$, there were few crystal structures of the hGFAT1 isomerase (ISOM) domain, and only very recently the full structure of this isoform was reported (22). Conversely, there is only one report focusing on the expression, purification and kinetics of the recombinant variation of the murine GFAT2 (mGFAT2) (24).

Therefore, studies concerning the characterization of physical-chemical properties of hGFAT2 are certainly needed. In the present work, we successfully expressed and purified the hGFAT2 in $E$. coli cells with and without a HisTag at C-terminal end, and demonstrated that hGFAT2 forms a tetramer in solution with full catalytic activity in both constructs. However, hGFAT2 exhibits a lower catalytic efficiency than those reported from other homologs or hGFAT1, but similar $K_{M}$ values. Using a series of enzyme assays, we detected a decoupling between the activities of both GFAT2 domains regardless the HisTag, generating ammonia leakage even in presence of Gln, and Fru-6P isomerization in Glc-6P. Despite the high identity between hGFAT1 and hGFAT2, the last is, in contrast, poorly inhibited by UDP-GlcNAc. Molecular dynamics simulations of the modeled hGFAT2 structure suggests the UDP-GlcNAc binding pocket may be partially blocked by interactions between the interdomain region and a highly flexible loop, whose structure was not elucidated in hGFAT1.

\section{Results}

\section{Recombinant human GFAT2 (rhGFAT2) forms tetramers in solution}

Our current knowledge on hGFAT rests on few studies that focused on hGFAT1 (20-22). However, recent evidences suggest an important association between hGFAT2 and metabolic pathologies $(18,25)$. In this context, a comprehensive characterization of hGFAT2 has become more pressing.

As previous literature diverges on the impact of fusion tags in both GlmS and GFAT activity (21), we expressed the recombinant hGFAT2 (rhGFAT2) protein in E. coli cells with and without a 6xHisTag at its C-terminal end. The best expression condition for both constructs was achieved after $0.5 \mathrm{mM}$ IPTG induction for $6 \mathrm{~h}$ at $25{ }^{\circ} \mathrm{C}$ under agitation. Although the majority of rhGFAT2 was expressed as inclusion bodies, a small fraction remained soluble (Suppl. Fig. 1A and B). To avoid improper refolding, we purified rhGFAT2 from the soluble fraction in a $\mathrm{Ni}^{+2} \mathrm{NTA}$ column and we obtained highly pure $(96.6 \%$ purity) HisTag-containing rhGFAT2 (rhGFAT2his) protein after a single step of affinity chromatography (Suppl. Fig. 1A, Table 1). Surprisingly, rhGFAT2 without HisTag (rhGFAT2 w/o tag) also bound to $\mathrm{Ni}^{+2} \mathrm{NTA}$ column, comprising therefore the first step for its purification, which reached high purity level (96.3\%) after an additional step of an anion exchange chromatography in a Q-sepharose column (Suppl. Fig. 1B, Table 1). Despite the high purity of both samples, final yield of purified rhGFAT2 w/o tag was 10 times lower than that of rhGFAT2-his (Table 1). The absence of the HisTag was further confirmed by Western blot analysis using an anti-HisTag monoclonal antibody (Suppl. Fig. 1C).

To evaluate the enzymatic activity of the purified enzymes, we performed an enzymatic assay to detect the GlcN-6P formation. As shown in Table 1, both rhGFAT2-his and rhGFAT2 w/o tag exhibited similar specific activity (Table 1), suggesting that HisTag at the C-terminal end has no effect on enzyme function. Based on these results and overall yield of purified enzymes, we decided to set rhGFAT2-his as the target for further biochemical characterization studies. 
Structural data regarding hGFAT1 indicates that this protein is found as a homotetramer in solution $(21,23)$. To assess whether rhGFAT2 also forms oligomers, we performed a cross-link assay using ethylene glycol bis(succinimidyl succinate) (EGS) as cross-linking agent and different amounts of rhGFAT2. We observed the presence of tetramers in all conditions analyzed, however we only achieved complete tetramerization when using $10 \mu \mathrm{g}$ of rhGFAT2 (Fig. 1A). To confirm this finding, we also performed a size exclusion chromatography using the Superdex 200 column. The fractions containing rhGFAT2 were eluted with the retention volume of $95 \mathrm{~mL}$ (Fig. 1B and C), indicating a molecular weight of approximately $300 \mathrm{kDa}$, which is consistent with the expected molecular weight of the rhGFAT2 tetramer. It is worth noting that an additional peak observed at approximately $74 \mathrm{~mL}$ corresponds to higher oligomers, possibly octamers (Fig. 1B and C). Altogether, our results demonstrate that rhGFAT2 can be successfully expressed in E. coli cells and the purified protein forms tetramers in solution.

\section{Enzyme kinetics of rhGFAT2}

In order to have a detailed perspective on hGFAT2 kinetics, we have measured its GlcN-6P synthetic activity (Suppl. Fig. 2A), using a modified Elson-Morgan reaction (26,27), and the ability of each domain to hydrolyze Gln or isomerase Fru-6P through coupled assays. All kinetic parameters are summarized in Table 2. Since the GlcN-6P synthetic activity of hGFAT is suggested to follow a bisubstrate ordered mechanism based on kinetic studies of $E$. coli GlmS $(19,28)$, we initially used that mechanistic model equation to fit our rate versus substrate curves (Suppl. Fig. 2A). However, we obtained an inconsistent (negative) value for ${ }^{\mathrm{Fru}-6 P} K_{M}$. Hence, we used Michaelis-Menten model to obtain apparent values of $K_{M}$ and $k_{\text {cat }}$. The app $K_{M}$ value for Fru-6P is higher than for Gln $(0.957$ and 0.763 $\mathrm{mM}$, respectively) (Table 2). Noteworthy, hGFAT2-his exhibited a low ${ }^{\text {app }} k_{\text {cat }}$ value for GlcN-6P synthesis (Table 2). Since the presence of HisTag did not affected the overall synthetic activity (Table 1 ), we checked if the $\mathrm{N}$-terminal methionine (Met1) was removed during heterologous expression, which could hamper the Cys2 to perform its role as catalyst and could explain the reduced activity of hGFAT2-his.
However, the peptide fingerprint suggests the Met1 was properly removed, as observed in the coverage of the peptides detected (Suppl. Fig. $3 \mathrm{~A}$ ), and confirmed by the fragmentation pattern of the N-terminal peptide 2CGIFAYMNYRVPR-14 (Suppl. Fig. 3B).

Using a coupled assay, we monitored the release of glutamic acid from Gln hydrolysis, by which we observed that hGFAT2-his is able to execute such activity even in absence of Fru-6P, but the presence of this phosphorylated monosaccharide increases 4 times the $k_{c a t}$ of aminohydrolysis reaction of (Table 2). The kinetic curves for the Gln hydrolysis show the increase in the rate bursted by Fru-6P (Suppl. Fig 2B), with a direct impact on the catalytic efficiency (Table 2). Whereas $k_{\text {cat }}$ of hGFAT2-his aminohydrolysing activity is in the same order of magnitude as of synthetic activity (around $0.03 \mathrm{~min}^{-1}$ ), the ISOM activity exhibits a 10-times higher $k_{\text {cat }}\left(0.322 \mathrm{~min}^{-}\right.$ ${ }^{1}$ ), and a $K_{M}$ of $0.711 \mathrm{mM}$ for the sugar (Table 2). In contrast to aminohydrolysis, the analysis of the ISOM activity curves in the presence of increasing concentrations of Gln indicates that hGFAT2-his performs the isomerization of Fru6P to Glc-6P even in higher concentrations of this amino acid (Suppl. Fig 2C), suggesting that part of the ammonia released from Gln hydrolysis is not used for GlcN-6P synthesis.

In order to confirm the unproductive hydrolysis of Gln, we used nuclear magnetic resonance (NMR) to detect directly the substrate consumption and the product formation from hGFAT2-his activity (Fig. 2A). Equimolar amounts $(3 \mathrm{mM})$ of $\mathrm{Gln}$ and Fru-6P was incubated in the presence or absence of hGFAT2his and the $1 \mathrm{D}{ }^{1} \mathrm{H}$ spectra were acquired (Supp. Fig. 4A and 4B). As expected, we observed the consumption of both Gln (reduced peaks at 2.15 and $2.48 \mathrm{ppm}$, corresponding to $\mathrm{H} \beta$ and $\mathrm{H} \gamma$, Fig. 2B) and Fru-6P (reduced peaks at 4.25 and 4.17 ppm, corresponding to $\mathrm{H} 1$ and H3, Fig. 2C) concomitantly with the generation of Glu (increased peaks at 2.07 and $2.36 \mathrm{ppm}$, corresponding to $\mathrm{H} \beta$ and $\mathrm{H} \gamma$, Fig. $2 \mathrm{~B}$ ) and $\alpha \mathrm{GlcN}$ 6P (increased peaks at 5.42 and $4.062 \mathrm{ppm}$, corresponding to $\mathrm{H} 1$ and H6, Fig. 2C) catalyzed by rhGFAT2-his. Noteworthy we noticed that peaks from both Glc-6P anomers increased during the reaction time course $(5.23,3.28,3.52$ and $4.00 \mathrm{ppm}$ corresponding to $\alpha \mathrm{H} 1, \beta \mathrm{H} 2, \beta \mathrm{H} 3$ 
and $\beta \mathrm{H} 4$, respectively, Fig. $2 \mathrm{C}$ ). The $\mathrm{H} 1$ from $\beta$ sugars were not detected, probably due to distortion of the spectra by the water suppression at $4.70 \mathrm{ppm}$. However, TOCSY spectrum at $\mathrm{t}=$ $84 \mathrm{~h}$ exhibits the correlation signals among H1, $\mathrm{H} 2$ and $\mathrm{H} 3$ from $\beta$ Glc-6P $(4.65,3.28$ and 3.52 ppm, respectively, Suppl. Fig. 4C). The TOCSY spectra also exhibits the correlation signals among $\mathrm{H} \alpha, \mathrm{H} \beta$ and $\mathrm{H} \gamma$ from both Gln and Glu (Suppl. Fig. 4C). Although close to the noise, the correlation signals between $\mathrm{H} 1$ and $\mathrm{H} 3$ from $\alpha \mathrm{GlcN}-6 \mathrm{P}$ (5.42 and $3.93 \mathrm{ppm}$, respectively), and among H1, H3 and $\mathrm{H} 5$ from $\alpha \mathrm{Glc}-6 \mathrm{P}$ (5.23, 3.75 and $3.92 \mathrm{ppm}$, respectively) were also observed (data not shown). The $\alpha \mathrm{H} 1$ signal from Glc-6P is present in a proportion of $1: 2.5$ relative to $\alpha \mathrm{H} 1$ of GlcN-6P measured in $1 \mathrm{D}{ }^{1} \mathrm{H}$ spectra, showing that rhGFAT2 partially acts as an isomerase even at equimolar concentrations of both substrates, corroborating the ISOM kinetics data. In addition, we did not observe spontaneous isomerization from Fru-6P to Glc-6P, spontaneous hydrolysis of Gln or GlcN-6P formation in the absence of the enzyme (Suppl. Fig. 4B). The oxidation of DTT (29) was the sole alteration in $1 \mathrm{D}{ }^{1} \mathrm{H}$ spectrum observed in the absence of the enzyme (Suppl. Fig. 4B).

In order to evaluate whether the innocuous effect of Gln on ISOM activity (Suppl. Fig. 2C) was due the presence of the C-terminal HisTag, we performed such assay with rhGFAT2 without tag. As observed for rhGFAT2-his, the addition of Gln in reaction medium did not only reduce the ISOM activity of rhGFAT2 w/o tag (Fig. 2D), but even enhances it suggesting that part of the ammonium released from Gln hydrolysis in GLN domain does not reach the ISOM domain.

To access the ammonia release from glutamine hydrolysis catalyzed by GFAT, we used a coupled assay with glutamic acid dehydrogenase in the presence of $\alpha$-ketoglutaric acid and NADH. The reduction in NADH absorbance was correlated to ammonia release using a standard curve of $\mathrm{NH}_{4} \mathrm{Cl}$. As we can see in Fig. 2E, the ammonia release increases with increasing concentrations of Gln, as expected, for both rhGFAT2 with and without HisTag. Fitting the curves with Michaelis-Menten equation, we observed that both enzymes reached a plateau at Gln saturating concentration $(10 \mathrm{mM})$, but the ammonia release from rhGFAT2 w/o tag is twice the values obtained from the HisTaggeg enzyme. Furthermore, the addition of Fru-6P, even at high concentrations, did not abolish the ammonia released to the medium for both the enzymes (Fig. $2 \mathrm{E}$ ), but actually enhancing the ammonia release, mainly for rhGFAT2 w/o tag. These data indicate that a great amount of the ammonia hydrolyzed from Gln is lost to the medium instead of reaching the ISOM domain for generating GlcN-6P.

\section{rhGFAT2 inhibition by UDP-GlcNAc}

UDP-GlcNAc, the final product of HBP, has been described as a potent inhibitor of glutaminase activity of hGFAT1 $(20,22)$. To examine whether UDP-GlcNAc is able to inhibit hGFAT2 as well, we assayed rhGFAT2's glutaminase activity in the presence of different concentrations of the activated monosaccharide. By plotting the results in a Dixon plot (Suppl. Fig. 5), we observed that UDP-GlcNAc is able to inhibit only $10 \%$ of rhGFAT2 activity, behaving as a partial inhibitor. This result shows that UDP-GlcNAc is a weak inhibitor of this GFAT isoform.

\section{Unstructured loop as a key for interdomain (miss)communication}

In an effort to understand the differences among the kinetic data reported for other GFATs and our results, we compared the sequences of GlmS (GFAT from $E$. coli), GFA (GFAT from $C$. albicans), hGFAT1 and hGFAT2. The alignment between GlmS and the hGFATs showed that the human variants exhibit an additional 46 residues sequence, from Lys211 to Val256 (hGFAT2 numbering) (Fig. 3A). This internal sequence is also present in GFA and is longer than those from hGFATs (Fig. 3A). Besides, these additional sequences are the most distinctive portion among hGFATs and GFA, and even between hGFAT1 and hGFAT2 (Fig. 3A): the identity of these short sequences between the human isoforms is only $49 \%$, in contrast to $79 \%$ when we compare the full sequences.

To better analyze the impact of these internal sequences on GFATs' structures, we generated tridimensional model for hGFAT2 using threading methods by subjecting the hGFAT2 amino acid sequence to I-TASSER and LOMETS servers. We opted, therefore, for the I-TASSER final model because it presented the best loop 
conformation. In this model, part of the loop (black arrow) folded into an $\alpha$-helix structure due to the interaction with intra-chain residues and the stabilization occurred by interaction with the interdomain connective portion (gray arrow, Fig. 3B). Although homology modelling could have used for this task, especially given the recently available full structure of hGFAT1 (22), there is a lack of structural information regarding exactly the sequence Lys211-Val256 throughout the experimental structures available. In addition, the model reliability is corroborated by the similar secondary structure content observed experimentally by circular dichroism for rhGFAT2-his (Suppl. Fig. 6, Table 3).

By using the same threading approach for hGFAT1 and GFA from C. albicans, we obtained the models for the complete structure of both. As shown in Fig. 3B, the additional sequence of hGFAT1 also forms an unstructured loop, similar to that from hGFAT2, close to the interdomain region. Whereas bigger and even less structured, the loop from GFA is also next to interdomain connective portion, contrasting to GlmS structure (PDB ID: 4AMV), in which such a loop is absent (Fig. 3B).

These results prompted us to investigate a possible function for the loop. Thus, we performed 3-replica molecular dynamics (MD) simulations of $500 \mathrm{~ns}$ each using the AMBER package. In fact, the loop was the most flexible region of overall GFAT's structure, as shown by root mean square fluctuation analysis (RMSF, Fig. 4A). During the simulation time, we observed that the loop approaches the protein itself in 2 replicas (Fig. 4B and 4C), but moves away from it in the $3^{\text {rd }}$ replica (Fig. 4D). By monitoring the network of interactions of loop residues, we noticed that Thr227, Asn230, Asn233, Arg238 and Arg241 are major players for the interaction with the interdomain region (mainly through residues Glu313 and Gln315, Fig. 5A-E and Suppl. Fig. 7A), and GLN (Glu269, Fig. 5A-D and 5F) and ISOM domains (Arg342 and Glu332, Fig. 5A-D, 5G and Suppl. Fig. 7B) in replicas 1 and 2.

Cluster analysis of MD frames from replicas 1 and 2 shows a heterogenous population distribution, in which few clusters - the ones reporting the loop in close contact with interdomain region and ISOM domain residues accounts for more than half of the frames (Suppl. Fig. 7D), while the same analysis of replica 3 produced a greater number of less populated clusters (Suppl. Fig. 7D). These results indicate that the interaction between the loop and protein residues ensures its stabilization.

To assess whether the loop dynamics had effects on the movement of the domains, we monitored the distance between key residues from catalytic sites of both domains - Cys2, the suggested Nterminal nucleophile for glutamine hydrolysis on glutaminanse domain, and Lys559 and Glu562 (equivalent to Lys485 and Glu488 from GlmS) from ISOM domain - to assess whether the domains' movement have an impact on them. In this way, we observed that, in the replicas in which the loop moves towards the protein (replicas 1 and 2), the domains did not move substantially, but in the replica in which the loop moves away from the protein (replica 3), they get closer by 4-5 ̊̊ (Fig. 5A-D, 5H and Suppl. Fig. 7C).

In order to understand how the structure of hGFAT2 could impact the ammonia leakage, we evaluate the neighborhood of Trp93 (unique Trp residue in this protein), equivalent to Trp74 in GlmS. Even though we observed conserved interactions between Trp93 and residues from Q, R- and C-loops - such as Tyr35, Leu675, Ala676, and Arg33 (Fig. 6A-C) - the C-tail is oriented upwards relative to that observed in GlmS structure bound to DON and Glc-6P (Fig. 6D). In hGFAT2, this feature seems to be derived from the interaction between the loop an interdomain region, and this last with R-loop. In Fig. 6E we can observe that the hydrogen bonds between Arg29 and side chains and backbone from residues Glu313, Leu314 and Gln316 forces a turn in the interdomain connection. In contrast, Arg22 in GlmS, although close to Tyr240, seemed not to form a hydrogen bond to such residue, nor to any other within the interdomain region (Fig. 6F). Moreover, the interdomain region sequence is distinct and three residues longer in both hGFAT1 and hGFAT2 compared to GlmS (Fig. 3), which can extend its structure linearly up to $9.6 \AA$. Together, these are the first enzymatic and structural data from the hGFAT2. 


\section{Discussion}

Despite the involvement of hGFAT2 in cancer aggressiveness, few studies have focused on the molecular and structural characterization of this protein. Here, we conducted a comprehensive study detailing the enzymatic properties of hGFAT2. We first expressed and purified the rhGFAT2 either fused or not to a HisTag at its Cterminal end. We showed that this enzyme mostly forms tetramers, in agreement with the data from hGFAT1 His6-Asn298 (21), and also forms higher order oligomeric structures, possibly octamers, at lower extent. Even though the presence of higher order oligomeric structures was not reported so far for eukaryotic GFATs, the formation of octamers could exert some regulatory role for hGFAT2, since the interplay between quaternary structures has been described for $E$. coli $\mathrm{GlmS}$ as a mechanism of enzyme inactivation (30).

Regarding the enzymatic properties of hGFAT2, the fitting of rate curves from GlcN-6P synthetic activity using the Michaelis-Menten equation resulted in ${ }^{a p p} K_{M}$ for Fru-6P and Gln similar to those described for mGFAT2 (24), hGFAT1 with no tags (23), and hGFAT1 His6-Asn298 $(21,22)$, but the and ${ }^{a p p} k_{c a t}$ were lower than those reported for either mammalian and prokaryotic GFATs $(20,21)$. When we fitted the data to ordered bisubstrate mechanistic model, based on kinetic studies with GlmS, we obtained an inconsistent value for ${ }^{F r u-6 P} K_{M}$, suggesting that hGFAT2 does not follow such kinetic model. This perspective is corroborated by the aminohydrolysing data, which shows that Gln is hydrolyzed by GFAT even in absence of Fru-6P, whereas the addition of this monosaccharide-phosphate increases the glutaminase catalysis by 4-fold. Such a feature was also observed for GFA from C. albicans (31). Altogether, these data suggest that Fru-6P binding is not essential for Gln binding, but acts as an activator of GFAT2's glutaminase activity. Since similar pattern of Fru-6P activation of aminohydrolysing activity was observed to rhGFAT2 without HisTag, we are confident that this phenomenon - the non-conditioning pattern of Fru-6P for Gln binding - is not an artifact derived from the HisTag. Although our data were not enough to determine the proper kinetic model that fits hGFAT2 GlcN-6P synthetic activity, it strongly indicates that this enzyme does not follow the ordered bi-bi substrate model, in contrast to the GlmS (19).

NMR spectroscopy was used to directly detect the progress of hGFAT2 catalysis. We found a considerable amount of Glc-6P, suggesting that hGFAT2 can partially act as an isomerase-only enzyme, regardless of Gln presence. This data is corroborated by the isomerase assays with rhGFAT2 either with or without HisTag. The phosphoglucose isomerase (PGI)-like activity has already been reported for GlmS (32) and for GFA in the absence of Gln (31). However, it is the first data describing that a human GFAT retains such a PGI-like activity, and moreover, that this activity is maintained even in the presence of Gln. Our findings are in agreement with previous report detecting Glc-6P upon cocrystalyzation of hGFAT1 with Gln and Fru-6P (22).

The isomerase data indicate, in the other hand, that part of Gln is lost in an unproductive hydrolysis. Indeed, the ammonia release assays suggest that Fru-6P does not prevent the loss of $\mathrm{NH}_{3}$ to the medium. To measure the efficiency of ammonia transfer, Floquet et al. (33) used the ratio between the $k_{c a t}$ of synthase and hemisynthase (glutaminase) activities, which, in their work, is $84 \%$ for GlmS. We and Ruegenberg et al. (22) observed an efficiency of ammonia transfer of approximately 50 and $47 \%$ for hGFAT2 and hGFAT1, respectively, indicating that human GFATs, in fact, have a higher rate of ammonia leakage. Structural data from GlmS point to the formation of a hydrophobic channel formed among Trp74 in the Q-loop and C-tail residues upon the binding of the two substrates as a key event for avoiding ammonia leakage (33$35)$. The movement of the Q-loop upon substrates binding was also observed for hGFAT1 (22), but it did not prevent the low efficiency of ammonia transfer. In this regard, kinetic and mutagenesis data from GFA suggest that deletion of a sequence from GLN domain disrupts the communication of both domains and hampers the GlcN-6P synthesis, but retains their aminohydrolysing and isomerase-only activities (31). In the present work, we observed that sequence from GFA is present in both hGFAT1 and hGFAT2, and folds in a highly flexible loop in the latter. The flexibility of this loop was also reported for hGFAT1 (22) and may be the reason for the difficulty in getting crystals from 
eukaryotic GFATs, as noticed by Nakaishi et al. (36).

Our MD simulation data suggest that the loop alternates among what could be seen as conformational states, in which it interacts with the interdomain region and ISOM domain, or shifts to an open-conformation. These results are in line with GlmS data from MD simulations and normal mode analysis (37). The hinge movement, which is reported to be performed solely by the hinge connection residues in GlmS, may be modulated by the loop residues in hGFAT2, and possibly in hGFAT1. In addition, the hinge connection sequence is distinct and is three residues longer in both hGFAT1 and hGFAT2 compared to GlmS, which could alter the domains' motions and impact the sealing of hydrophobic channel by changing the orientation of R- and Q-loops to C-tail. Thus, our data suggest that the loop evolved as an additional regulatory mechanism, which is corroborated by having conserved phosphorylation sites in GFA $(31,38)$, GFAT from Drosophila melanogaster (39), mGFAT2 (24) and hGFAT1 (40-42), a posttranslational modification that alter their enzymatic properties with direct impact in cell biology (43).

The differences among hGFAT1 and hGFAT2 goes beyond the hinge connection and loop sequences, or their catalytic efficiency: they also differ in susceptibility to allosteric inhibition by UDP-GlcNAc $(20,22)$. Our data is in accordance with previous work describing the partial inhibition of mGFAT2 by UDP-GlcNAc (24). The close interaction observed between the loop residues and Arg342, near the allosteric site, could lead to pocket hidrance and may explain the poor inhibition.

Despite these number of contrasting properties of hGFAT2 and hGFAT1, it is worth noting that both isoforms are simultaneously expressed in the vast majority of cell types so far analyzed, although their ratio vary among them $(7,18,25)$. Moreover, several evidences have shown that their expression is modulated by different factors (Xpb1s for hGFAT1 and NR4A1 for hGFAT2, for example) $(25,44)$ and is observed in distinct circumstances $(18,45,46)$. This sheds light on the relevance of the difference between the characteristics of these two enzymes, suggesting that cells can take advantage of it by changing the ratio hGFAT1/hGFAT2. In addition, we cannot exclude the possibility that hGFAT1 and hGFAT2 form heterotetramers. Altogether, our work provides the first comprehensive set of data on the structure, kinetics and mechanics of hGFAT2. Our results contribute to the knowledge of physiological roles and differences between GFAT isoforms. More studies addressing the interaction of hGFAT2 to substrates and ligands are important.

\section{Experimental procedures}

\section{Construction of pET-hGFAT2 plasmids}

The $g f p t 2$ gene was amplified from pCMV6-AC plasmid (Origene, USA) by PCR and inserted into bacterial expression plasmid pET23a (Novagen, USA) in order to construct either pET-hGFAT2 with and without HisTag. For both plasmids, the gene amplification was performed using the same sense primer 5 GGAATTCCATATGTGCGGAATCTTTGCCT AC 3' (containing a restriction site for Nde I), but distinct antisense primers: 5 , ATAAGAATGCGGCCGCTTCCACAGTTAC AGACTTG 3' for hGFAT2-His, and 5' ATAAGAATGCGGCCGCTTATTCCACAGTT ACAGACTTG 3' for hGFAT2 without tag (both containing a restriction site for Not I), this last containing a stop codon right after the protein sequence. The reactions were performed as follows: 2 min at $94{ }^{\circ} \mathrm{C}$ followed by 35 cycles of $1 \mathrm{~min}$ at $94{ }^{\circ} \mathrm{C}, 1 \mathrm{~min}$ at $52{ }^{\circ} \mathrm{C}$, and $2 \mathrm{~min}$ at 68 ${ }^{\circ} \mathrm{C}$, with an extension step of $7 \mathrm{~min}$ at $68^{\circ} \mathrm{C}$. The amplified genes were then electrophoresed in $1 \%$ agarose gel followed by purification using PCR purification kit (Qiagen, USA). Both purified genes and plasmids were digested with Nde I and Not I prior to ligation using the T4 DNA ligase (New England Biolabs, UK). The recombinant plasmids pET-hGFAT2 (without tag) and pEThGFAT2-his were inserted into electrocompetent E. coli DH5 $\alpha$ cells and positive colonies were subjected to a PCR colony using the abovementioned primers. The reactions was performed as follows: $2 \mathrm{~min}$ at $94{ }^{\circ} \mathrm{C}$ followed by 35 cycles of $1 \mathrm{~min}$ at $94{ }^{\circ} \mathrm{C}, 1 \mathrm{~min}$ at $52^{\circ} \mathrm{C}$, and $2 \mathrm{~min}$ at $72^{\circ} \mathrm{C}$, with an extension step of $7 \mathrm{~min}$ at $72{ }^{\circ} \mathrm{C}$. True positive clones were isolated and sequenced by using an ABI PRISM dye 
terminator cycle sequencing core kit (Applied Biosystems, USA).

\section{Expression of recombinant hGFAT2s (rhGFAT2s) in E. coli}

Chemically competent $E$. coli Codon plus cells (Novagen, USA) were transformed with $200 \mathrm{ng}$ of the pET-hGFAT2 (with or without tag) plasmids, and positive clones were selected in an LB-agar medium containing $100 \mu \mathrm{g} / \mathrm{mL}$ ampicillin and $34 \mu \mathrm{g} / \mathrm{mL}$ chloramphenicol at 37 ${ }^{\circ} \mathrm{C}$ overnight. A single positive colony was preinoculated in $10 \mathrm{~mL}$ of $\mathrm{LB}$ medium containing $100 \mu \mathrm{g} / \mathrm{mL}$ ampicillin and $34 \mu \mathrm{g} / \mathrm{mL}$ chloramphenicol, and this culture was stirred at $220 \mathrm{rpm}$ at $37^{\circ} \mathrm{C}$ overnight. The overnight culture was diluted to $1: 50$ in $1 \mathrm{~L}$ of fresh antibioticcontaining medium and grown at $37^{\circ} \mathrm{C}$ until an optical density (O.D.600nm) of approximately 0.7 0.8 was reached. The induction of protein expression was conducted with $0.5 \mathrm{mM}$ IPTG followed by $6 \mathrm{~h}$ of expression at $25^{\circ} \mathrm{C}$ with 220 rpm stirring. Thus, the cells were harvested by centrifugation at 5,000 $\mathrm{x} g$ for $20 \mathrm{~min}$ at $4{ }^{\circ} \mathrm{C}$, and the total-cell lysate was prepared.

\section{Purification of rhGFAT2s}

The pellet was suspended in $25 \mathrm{~mL}$ of Buffer A (20 mM Tris- $\mathrm{HCl} \mathrm{pH}$ 7.5, $500 \mathrm{mM} \mathrm{NaCl}, 1 \mathrm{mM}$ DTT and $0.5 \% \mathrm{NP}-40$ ) in the presence of $1 \mathrm{mM}$ PMSF and $0.5 \mu \mathrm{g} / \mathrm{mL}$ of each protease inhibitor: aprotinin, bestatin, pepstatin and E-64 (Sigma Aldrich, USA). Then, $5 \mathrm{mg} / \mathrm{mL}$ of lysozyme, 10 $\mu \mathrm{g} / \mathrm{mL}$ of DNase $\mathrm{A}$, and $5 \mathrm{mM}$ of magnesium chloride were added, and the solution was incubated for $30 \mathrm{~min}$ at $4{ }^{\circ} \mathrm{C}$ with stirring. The total-cell lysate was sonicated using 10 cycles of $15 \mathrm{sec}$ on and $1 \mathrm{~min}$ off at $40 \%$ amplitude, followed by centrifugation at $37,200 \times g$ for 20 $\min$ at $4{ }^{\circ} \mathrm{C}$.

The supernatant fraction containing the rhGFAT2 protein (with or without tag) was subjected to purification using a $\mathrm{Ni}^{+2} \mathrm{NTA}$ affinity column (HisTrap HP $5 \mathrm{~mL}$, GE Healthcare, USA). The column was equilibrated with 10 column volumes (CV) of Buffer A prior to load the sample at a flow of $1 \mathrm{~mL} / \mathrm{min}$. After this step, the nonspecific ligands were removed by washing the column with $5 \mathrm{CV}$ of Buffer A. The elution was performed using a gradient of Buffer $\mathrm{A}$ and
Buffer B (Buffer A with the addition of $0.5 \mathrm{M}$ imidazole) at a flow rate of $2 \mathrm{~mL} / \mathrm{min}$. All collected samples were analyzed by SDS-PAGE, and the tubes containing the purified rhGFAT2his were pooled and dialyzed against Storage buffer (20 mM Tris- $\mathrm{HCl} \mathrm{pH} 7.5,150 \mathrm{mM} \mathrm{NaCl}$, $1 \mathrm{mM}$ DTT, and 5\% glycerol).

The purification of rhGFAT2 w/o tag required an additional step of purification with an anion exchange chromatography. The SDS-PAGE analyzed fractions from HisTrap column which contained the rhGFAT2 w/o tag were pooled and dialyzed overnight against buffer C (20 mM Tris$\mathrm{HCl} \mathrm{pH} \mathrm{8.0,} 1 \mathrm{mM}$ DTT, 0.5\% NP40) with 150 $\mathrm{mM} \mathrm{NaCl}$. The dialyzed protein was diluted in buffer $\mathrm{C}$ to reach $50 \mathrm{mM} \mathrm{NaCl}$ immediately before loading to a Q-sepharose HP column (5 $\mathrm{mL}$, GE Healthcare, USA), previously equilibrated with $10 \mathrm{CV}$ of Buffer $\mathrm{C}$. The nonspecific ligands were removed by washing the column with $5 \mathrm{CV}$ of Buffer $\mathrm{C}$. The elution was performed using a gradient of Buffer $\mathrm{C}$ and Buffer D (Buffer $\mathrm{C}$ with the addition of $0.5 \mathrm{M}$ $\mathrm{NaCl})$ at a flow rate of $2 \mathrm{~mL} / \mathrm{min}$. All collected samples were analyzed by SDS-PAGE, and the tubes containing the purified rhGFAT2 w/o tag were pooled and dialyzed against Storage buffer.

\section{Western Blot}

The purified proteins ( 2 ug each) were submitted to SDS-PAGE in $10 \%$ acrylamide gel, and electrofransfered to nitrocellulose membrane. The membrane was blocked with $3 \%(\mathrm{w} / \mathrm{v})$ bovine serum albumin in Tris-buffered saline with $0.1 \% \quad(\mathrm{v} / \mathrm{v})$ Tween-20, and incubated overnight at $4{ }^{\circ} \mathrm{C}$ with anti-His (Santa Cruz Biotechnologies, USA). The membrane was then washed, incubated for $1 \mathrm{~h}$ under agitation with the secondary antibody (anti-mouse, Santa Cruz). After a second round of washing, the labeled membrane was developed with Femto ECL (Thermo Fisher Scientific) and exposed to ImageQuant LAS 500 (GE Healthcare). The membrane was stripped and labelled with antiGFAT2 (Cell Signaling Technologies, USA) following the same procedure described above.

\section{Cross-linking assay}

The purified rhGFAT2 protein $(3,5$ and $10 \mu \mathrm{g})$ was incubated in PBS buffer in the presence or 
absence of $1 \mathrm{mM}$ EGS for $30 \mathrm{~min}$ at room temperature. The reactions were stopped with addition of $30 \mathrm{mM}$ of Tris- $\mathrm{HCl}$ pH 8.0. Approximately $10 \mu \mathrm{g}$ of each sample were analyzed by a gradient SDS-PAGE assay (BioRad, USA) followed by Coomassie Brilliant Blue staining.

\section{Size exclusion chromatography}

The purified rhGFAT2-his protein was subjected to a size exclusion chromatography using a Superdex 200 column (GE Healthcare, USA). The column was equilibrated with $1 \mathrm{CV}$ of 20 $\mathrm{mM}$ Tris-HCl pH 7.5, $150 \mathrm{mM} \mathrm{NaCl}, 1 \mathrm{mM}$ DTT, $0.5 \%$ NP-40 prior to sample loading at a flow rate of $1 \mathrm{~mL} / \mathrm{min}$. The fractions were collected and analyzed by SDS-PAGE. The molecular weight of rhGFAT2 oligomer was estimated according to the retention time of standard proteins (Thyroglobulin - $669 \mathrm{kDa}$, Apoferritin - $443 \mathrm{kDa}$, $\beta$-amilase - $200 \mathrm{kDa}$, BSA - $66 \mathrm{kDa}$, Carbonic anhydrase - $29 \mathrm{kDa}$, and Citocrome $\mathrm{C}$ oxidase $12.4 \mathrm{kDa}$ ) acquired from Sigma Co.

\section{Characterization of rhGFAT2-his products by NMR}

Solution of rhGFAT2-his was exchanged with deuterated sodium phosphate buffer $(50 \mathrm{mM} \mathrm{pH}$ 7.4, with $150 \mathrm{mM} \mathrm{NaCl}$ and $1 \mathrm{mM}$ DTT) using four cycles of dilution and concentration with Amicon Ultra 30K NMWL (Millipore, USA). Two hundred microliters of $100 \mu \mathrm{g}$ protein solution were incubated with $3 \mathrm{mM}$ of Fru-6P and $3 \mathrm{mM}$ of Gln in Shigemi tubes. In order to check for spontaneous product formation or substrate consumption, the same amounts of Gln and Fru$6 \mathrm{P}$ were incubated with $200 \mu \mathrm{L}$ of the deuterated buffer in which the protein were conditioned. NMR spectra were obtained at a probe temperature of $298 \mathrm{~K}$ on a Bruker Avance III 500 MHz equipped with a $5 \mathrm{~mm}$ self-shielded gradient triple resonance probe. The GFAT reaction products were monitored by unidimensional ${ }^{1} \mathrm{H}$ spectra, performed according to the Bruker pulse sequence zgesgp. The product characterization was assisted by total correlation spectroscopy (TOCSY) spectra, which were recorded using mlevesgpph pulse sequence with a mixing time of $80 \mathrm{~ms}$ and 64 scans per $\mathrm{t} 1$ increment. For each scan, 8192 transients of 256 complex data points were acquired to a $10.0 \mathrm{ppm}$ spectral width. The spectra were multiplied with a square cosine bell function in both dimensions and zero-filled twofold. The data acquisition and analysis were performed using spectrometer software Topspin 3.6 (Bruker Corporation).

\section{Enzyme assays}

\section{GlcN-6P Synthetic activity}

The specific GlcN-6P synthetic activity from rhGFAT2-his and rhGFAT2 w/o tag was assayed by incubating $100 \mu \mathrm{g}$ of each protein with $10 \mathrm{mM}$ Fru-6P, $10 \mathrm{mM}$ Gln, $1 \mathrm{mM}$ DTT in PBS pH 7.4 (100 $\mu \mathrm{L}$ of final reaction volume) for $1 \mathrm{~h}$ at $37^{\circ} \mathrm{C}$ under agitation. The glucosamine-6-phosphate $(\mathrm{GlcN}-6 \mathrm{P})$ formed in the reaction mixtures was determined as described by Queiroz et al. (27), based on Elson \& Morgan (26). Briefly, $10 \mu \mathrm{L}$ of $1.5 \%$ acetic anhydride (Sigma, USA) and $50 \mu \mathrm{L}$ of $100 \mathrm{mM}$ sodium tetraborate was added to the reaction mixture and incubated at room temperature for $5 \mathrm{~min}$ under agitation. The samples were then incubated at $80^{\circ} \mathrm{C}$ for $25 \mathrm{~min}$, cooled down at $4{ }^{\circ} \mathrm{C}$ for $5 \mathrm{~min}$, and spun down for removing precipitated protein. The resultant acetylated GlcN-6P was derivatized with $130 \mu \mathrm{L}$ of Ehrlich reagent in a 96-wells microplate incubated for $30 \mathrm{~min}$ at $37^{\circ} \mathrm{C}$ and finally read at $585 \mathrm{~nm}$ in microplate reader (SpectraMax 190, Molecular Probes, USA). The absorbance of the samples not incubated with GFAT substrates was discounted and the concentration of GlcN-6P was determined comparing the resultant absorbance of the samples with GlcN-6P standards processed in the same manner. The specific activity was expressed as units ( $\mu \mathrm{mol}$ of GlcN-6P synthesized per min at $37^{\circ} \mathrm{C}$ ) per $\mathrm{mg}$ of protein.

For kinetic analysis, the assay was performed as described, but with the following modifications: rhGFAT2-his was incubated with variable concentrations of one of the substrates (Fru-6P or Gln, at 0.156, 0.313, 0.625, 1.25, 2.0, and 2.5) while the other was fixed at saturating concentration $(10 \mathrm{mM})$; the reaction mixtures were incubated by multiple time points up to 15 min, counted from the addition of the enzyme (time point 0 min was considered as the reaction mixture without the enzyme). At the end of incubation time, the reaction mixtures were processed for GlcN-6P derivatization as for the specific activity. For calculation of kinetic 
parameters, the progression curves were plotted, and the initial velocity was calculated (related to each substrate). The apparent kinetic parameters $\left(k_{c a t}\right.$ and $\left.K_{M}\right)$ were determined by direct fit of the rate versus substrate concentration data to the rate equation for Michaelis-Menten using GraphPad Prism version 8 (GraphPad, USA). The data were also submitted to fitting to both simple MichealisMenten equation and ordered bisubstrate mechanistic equation using GraFit version 7 (Erithacus Software, USA).

\section{Aminohydrolysing (glutaminase) activity}

GFAT glutaminase activity was determined using a coupled assay, based on Ye et al.(47). In the assay, the glutamate released by GFAT activity is oxidized by glutamic acid dehydrogenase (GDH) with concomitant 3-acetylpyridine adenine dinucleotide (APAD) reduction. The amidotransferase reaction was carried out in 200 $\mu \mathrm{L}$ of $20 \mathrm{mM}$ phosphate buffer $\mathrm{pH} 7.4$ with $50 \mu \mathrm{g}$ of rhGFAT2-his, containing variable concentrations of $\operatorname{Gln}(0.156,0.313,0.625,1.25$, 2.5, 5.0, and $10.0 \mathrm{mM}$ ), and Fru-6P. APADH formation was monitored continuously by absorbance at $370 \mathrm{~nm}$ in Spectramax 190 instrument (Molecular Devices, CA, USA) for 1 $\mathrm{h}$ at $37{ }^{\circ} \mathrm{C}$. The APADH concentration was derived from its molar extinction coefficient. Kinetic parameters were determined as described for GlcN-6P synthetic activity.

\section{$\underline{\text { Isomerase activity }}$}

The isomerization of Fru-6P to Glu-6P by rhGFAT2 was assayed as described by Olchowy et al. (31). In brief, $50 \mu \mathrm{g}$ of rhGFAT2-his were incubated with variable concentrations of Fru-6P in $200 \mu \mathrm{L}$ of $50 \mathrm{mM}$ Tris- $\mathrm{HCl} \mathrm{pH} 7.4$ with $1 \mathrm{mM}$ DTT, $0.5 \mathrm{mM}$ NADP (Sigma, USA) and 2.5 $\mathrm{mU} / \mu \mathrm{L}$ glucose-6-phosphate dehydrogenase (G6PD from Saccharomyces cerevisiae, Sigma, USA). Some assays were performed in the presence of variable concentrations of Gln $(0.5$, $0.625,1.25,2.5,5.0$ and $10 \mathrm{mM}$ ) with fixed $(0.625,2.5$ and $10 \mathrm{mM})$ concentrations of Fru-6P. NADPH formation was monitored continuously by absorbance at $340 \mathrm{~nm}$ in Spectramax 190 instrument (Molecular Devices, CA, USA) for 30 $\min$ at $25{ }^{\circ} \mathrm{C}$. The NADPH concentration was derived from its molar extinction coefficient.
Kinetic parameters were determined as described for GlcN-6P synthetic activity.

To evaluate the ISOM specific activity of rhGFAT2 with or without HisTag, each enzyme was incubated with $10 \mathrm{mM}$ Fru-6P in the presence or absence of $10 \mathrm{mM}$ Gln in the same conditions described above. The absorbance at $340 \mathrm{~nm}$ was read at the end of $30 \mathrm{~min}$. The specific ISOM activity was expressed as units ( $\mu \mathrm{mol}$ of NADPH synthesized per min at $37{ }^{\circ} \mathrm{C}$ ) per $\mathrm{mg}$ of the enzyme.

\section{Ammonia release}

The release of ammonia from Gln hydrolysis catalyzed by rhGFAT 2 was monitored by using the GDH in reverse direction, based on Floquet et al. (33). In this perspective, the ammonia released by GFAT activity is used in reductive amination of $\alpha$-ketoglutaric acid $(\alpha \mathrm{KG})$, thereby with NADH oxidation. The assays were carried out by incubating $50 \mu \mathrm{g}$ of rhGFAT2 (with or without HisTag) with variable concentrations of Gln $(0.25,1.25$ and $10.0 \mathrm{mM})$, or with a fixed saturating concentration of Gln $(10 \mathrm{mM})$ and variable concentrations of Fru- $6 \mathrm{P}(0.25,1.25,2.5$, 10 , and $20 \mathrm{mM}$ ), in $200 \mu \mathrm{L}$ of $20 \mathrm{mM}$ phosphate buffer $\mathrm{pH} 7.4$ with $1 \mathrm{mM}$ DTT, $0.25 \mathrm{mM}$ NADH, $2.5 \mathrm{mM} \alpha \mathrm{KG}$, and $30 \mathrm{mU} / \mu \mathrm{L} \mathrm{GDH}$. Reaction mixtures with the enzymes and the variable concentrations of $\operatorname{Gln}(0.25,1.25$ and $10.0 \mathrm{mM})$, but without $\alpha \mathrm{KG}$ were used as blanks for their correspondent reactions. The NADH consumption was assessed by absorbance at 340 $\mathrm{nm}$ in Spectramax 190 instrument after $30 \mathrm{~min}$ incubation at $37{ }^{\circ} \mathrm{C}$. The NADH consumed was taken as the difference between the final absorbance of each of the samples and their correspondent blanks without $\alpha \mathrm{KG}$. The ammonia released was determined comparing the resultant absorbance difference of the samples with the ones from $\mathrm{NH}_{4} \mathrm{Cl}$ standards. The results were expressed as units $\mu \mathrm{mol}$ of ammonia per min per mg of protein.

\section{Peptide fingerprinting}

Five micrograms of rhGFAT2-his was reduced with $3 \mathrm{mM}$ DTT at $60{ }^{\circ} \mathrm{C}$ for $30 \mathrm{~min}$, and carbamidomethylated with $9 \mathrm{mM}$ iodoacetamide at room temperature for $30 \mathrm{~min}$ in the dark. The protein was then digested with Trypsin Gold 
(Promega) 1:100 at $37{ }^{\circ} \mathrm{C}$ overnight in $10 \mathrm{mM}$ ammonium bicarbonate $\mathrm{pH} 8.0$ and the resultant peptides were cleaned up with POROS 20 R2 (Applied Biosystens). The sample was dried under vacuum, solubilized in $2 \%$ acetonitrile and $0.1 \%$ formic acid (FA) in water and submitted to LC-MS in Nexera UPLC system (Nexera, Shimadzu, Japan) coupled to maXis Impact mass spectrometer (Q-TOF configuration, Bruker Daltonics) equipped with electrospray ionization source. Separation was accomplished in an Acquity CSH C18 UPLC column (150 m x $1 \mathrm{~mm}$, $1.7 \mu \mathrm{m}$ particle size, Waters) at $50{ }^{\circ} \mathrm{C}$ using a flow rate of $130 \mu \mathrm{L} / \mathrm{min}$. After equilibration with $0.1 \%$ formic acid in water containing $2 \%$ acetonitrile, the peptides were injected and eluted using the following acetonitrile gradient: $2-8 \%$ in $2 \mathrm{~min}, 8$ $25 \%$ in $28 \mathrm{~min}, 25-50 \%$ in $10 \mathrm{~min}$ and kept at $50 \%$ for $2 \mathrm{~min}, 50-95 \%$ in $1.5 \mathrm{~min}$ and kept at $95 \%$ for $6 \mathrm{~min}$. The electrospray source parameters were set as following: capillary voltage at $4.5 \mathrm{kV}$, end plate offset at $-500 \mathrm{~V}$, nebulizer gas at $1.2 \mathrm{bar}$, dry gas at $8 \mathrm{~L} / \mathrm{min}$, and dry temperature at $200{ }^{\circ} \mathrm{C}$. Mass spectra were acquired in the positive-ion mode over the range $\mathrm{m} / \mathrm{z}, 50-1500$ in data dependent acquisition fragmentation mode at 1 Hz. The mass spectrometer was internally calibrated using $100 \mu \mathrm{M}$ sodium formate solution.

The mass spectrometry data was processed using Mascot Search engine (Matrix Science) in BioTools software version 3.2 (Bruker Daltonics). The MS/MS data were searched against both the Uniprot Human amino acid sequence database and the hGFAT2 sequence, with and without Met1, for protein/peptide identification. The search was set up for full tryptic peptides with a maximum of 2 missed cleavage sites; carbamidomethyl cysteine and oxidized methionine were included as fixed and variable modifications, respectively. The precursor mass tolerance was set to $10 \mathrm{ppm}$, and the maximum fragment mass error was set to 0.05 Da.

\section{Circular Dichroism}

The circular dichroism (CD) experiments were conducted with hGFAT2-his in a Chirascan Circular Dichroism Spectropolarimeter (Applied Photophysics, UK) at $20^{\circ} \mathrm{C}$ using a quartz cuvette with a $0.01 \mathrm{~cm}$ path length. Spectra from three scans from 260 to $190 \mathrm{~nm}$ at a $30 \mathrm{~nm} / \mathrm{min}$ speed were averaged, and the buffer baselines were subtracted from their respective sample spectra. As a negative control, the protein was further denatured with $6 \mathrm{M}$ guanidine- $\mathrm{HCl}$ and $\mathrm{CD}$ scans were repeated. The secondary structure content was estimated from fitting the far-UV CD spectra using the different algorithms, such as CDSSTR, K2D (48) and SELCON3 (49,50), which is available on the Dichroweb server $(51,52)$.

\section{Modelling GFAT structures}

Multiple sequence alignments of hGFAT2 and its orthologous enzymes were carried out using ClustalO (53). The hGFAT2 sequence was submitted to the I-TASSER (Iterative Threading Assembly Refinement) (54) server to achieve a complete structural model. The hGFAT1 and GFA (from $C$. albicans) sequences were submitted to I-TASSER server as well. The best models were selected based on the higher confidence scores and template modeling scores.

\section{Molecular dynamics simulation}

The best hGFAT2 model was further submitted to molecular dynamics simulation to investigate its conformational stability. Molecular Dynamics (MD) simulations were performed using the AMBER v. 14 software package (55) with the AMBER ff14SB force field (56). Explicit TIP3P water molecules (57) were used to solvate the hGFAT2 structure model in a cubic water box, using periodic boundary conditions. The protonation state of protein residues was assigned according to the values at $\mathrm{pH} 7.4$ using the PROPKA software (58). The system was then neutralized by adding $1 \mathrm{Na}^{+}$ion to the simulation box. SHAKE algorithm (59) was applied to constrain all the bonds involving hydrogen atoms. Long-range electrostatic interactions were calculated with the PME method (60). The nonbonded interactions (Coulomb and van der Walls) were calculated using cutoffs of $8 \AA$.

The system was energy-minimized using 25000 cycles of Steepest Descent algorithm followed by 25000 cycles of Conjugated Gradient method with and without position restraint of $5 \mathrm{kcal} \mathrm{mol}^{-}$ ${ }^{1} \AA^{-2}$ for protein heavy atoms. The system was gradually heated from 0.15 to $300 \mathrm{~K}$ over 200 ps. Langevin thermostat (61) with a collision 
frequency of $0.067 \mathrm{ps}^{-1}$ was used to control the temperature under a canonical ensemble and applying positional restrictions to the protein heavy atoms. Next, the pressure was applied until stabilized at 1 bar, using Berendsen barostat (62), by $7.5 \mathrm{~ns}$ under an isothermal and isobaric MD simulation with protein heavy atoms restrained to adjust the solvent density. The force constant for restraint was decreased gradually from 3 to $0 \mathrm{kcal}^{-}$ $1 \AA^{-2}$. Finally, $500 \mathrm{~ns}$ of production MD simulation with a time step of $2 \mathrm{fs}$ was performed at a constant temperature of $300 \mathrm{~K}$ using Langevin themostat with a collision frequency of
$5.0 \mathrm{ps}^{-1}$ and a constant pressure of $1 \mathrm{bar}$ controlled by Berendsen barostat (62) with a 1 ps pressure relaxation time. The MD trajectory was saved every $100 \mathrm{ps}$ for analysis. The MD simulations replicas were performed by using different seeds to generate initial velocities. The analysis and figures were made using PyMol (The PyMOL Molecular Graphics System, Version 1.2r3pre, Schrödinger, LLC.) and VMD (63) programs. 


\begin{abstract}
Abbreviations
$\alpha \mathrm{KG}, \alpha$-ketoglutaric acid; APAD, 3-acetylpyridine adenine dinucleotide; APADH, reduced form of APAD; EGS, ethylene glycol bis(succinimidyl succinate); Fru-6P, fructose-6-phosphate; G6PD, glucose-6-phosphate dehydrogenase; GDH, glutamic acid dehydrogenase; GFAT, glutamine:fructose6-phosphate amidotransferase; GFA, glutamine:fructose-6-phosphate amidotransferase from C. albicans; Glc-6P, glucose-6-phosphate; GlcN-6P, glucosamine-6-phosphate; GlmS, glucosamine-6phosphate synthase from E. coli; GLN, glutaminase (in reference to protein domain or activity); HBP, hexosamine biosynthetic pathway; hGFAT, human GFAT; IPTG, isopropyl- $\beta$-D-thiogalactoside; ISOM, isomerase (in reference to protein domain or activity; LC-MS, liquid chromatography coupled to mass spectrometry; MD, molecular dynamics; mGFAT, murine GFAT; PGI, phosphoglucose isomerase; rhGFAT, recombinant human GFAT; RMSF, root mean square fluctuation; TOCSY, total correlation spectroscopy.
\end{abstract}

\title{
Funding
}

This work was supported by the Conselho Nacional de Desenvolvimento Científico e Tecnológico (CNPq), Fundação Carlos Chagas Filho de Amparo à Pesquisa do Estado do Rio de Janeiro (FAPERJ), and Coordenação de Aperfeiçoamento de Pessoal de Nível Superior (CAPES) - Finance Code 001. This study was also supported by Programa Nacional de Apoio ao Desenvolvimento da Metrologia, Qualidade e Tecnologia (PRONAMETRO) from the Instituto Nacional de Metrologia, Qualidade e Tecnologia (INMETRO).

\section{Acknowledgements}

We thank Centro Nacional de Ressonância Magnética Nuclear (CNRMN - CENABIO, UFRJ), Centro de Espectrometria de Massas de Biomoléculas (CEMBIO, UFRJ), Plataforma de Expressão e Purificação de Proteínas com Interesse Biotecnológico (PEPIBiotec, UFRJ), and Plataforma de Imunoanálise (PIA, UFRJ). T.V.A.F. acknowledges Instituto Nacional de Metrologia, Qualidade e Tecnologia (Programa Nacional de Apoio ao Desenvolvimento da Metrologia, Qualidade e Tecnologia - PRONAMETRO) for a scholarship.

Conflict of interest: The authors declare no conflicts of interest regarding this manuscript.

\section{References}

1. Handa, K., and Hakomori, S. I. (2012) Carbohydrate to carbohydrate interaction in development process and cancer progression. Glycoconj J 29, 627-637

2. Vasconcelos-dos-Santos, A., Oliveira, I. A., Lucena, M. C., Mantuano, N. R., Whelan, S. A., Dias, W. B., and Todeschini, A. R. (2015) Biosynthetic machinery involved in aberrant glycosylation: promising targets for developing of drugs against cancer. Front. Oncol. 5, 23

3. Marshall, S., Bacote, V., and Traxinger, R. R. (1991) Discovery of a metabolic pathway mediating glucose-induced desensitization of the glucose transport system. Role of hexosamine biosynthesis in the induction of insulin resistance. J Biol Chem 266, 4706-4712

4. Massiere, F., and Badet-Denisot, M. A. (1998) The mechanism of glutamine-dependent amidotransferases. Cell Mol Life Sci 54, 205-222

5. Wu, G., Sun, Y., Qu, W., Huang, Y., Lu, L., Li, L., and Shao, W. (2011) Application of GFAT as a novel selection marker to mediate gene expression. PLoS One 6, e17082

6. Ghosh, S., Blumenthal, H. J., Davidson, E., and Roseman, S. (1960) Glucosamine metabolism. V. Enzymatic synthesis of glucosamine 6-phosphate. J Biol Chem 235, 1265-1273

7. Oki, T., Yamazaki, K., Kuromitsu, J., Okada, M., and Tanaka, I. (1999) cDNA cloning and mapping of a novel subtype of glutamine:fructose-6-phosphate amidotransferase (GFAT2) in human and mouse. Genomics 57, 227-234 
8. Niimi, M., Ogawara, T., Yamashita, T., Yamamoto, Y., Ueyama, A., Kambe, T., Okamoto, T., Ban, T., Tamanoi, H., Ozaki, K., Fujiwara, T., Fukui, H., Takahashi, E. I., Kyushiki, H., and Tanigami, A. (2001) Identification of GFAT1-L, a novel splice variant of human glutamine: fructose-6phosphate amidotransferase (GFAT1) that is expressed abundantly in skeletal muscle. J Hum Genet 46, 566-571

9. DeHaven, J. E., Robinson, K. A., Nelson, B. A., and Buse, M. G. (2001) A novel variant of glutamine: fructose-6-phosphate amidotransferase-1 (GFAT1) mRNA is selectively expressed in striated muscle. Diabetes 50, 2419-2424

10. Hebert, L. F., Jr., Daniels, M. C., Zhou, J., Crook, E. D., Turner, R. L., Simmons, S. T., Neidigh, J. L., Zhu, J. S., Baron, A. D., and McClain, D. A. (1996) Overexpression of glutamine:fructose-6phosphate amidotransferase in transgenic mice leads to insulin resistance. J Clin Invest 98, 930-936

11. Srinivasan, V., Sandhya, N., Sampathkumar, R., Farooq, S., Mohan, V., and Balasubramanyam, M. (2007) Glutamine fructose-6-phosphate amidotransferase (GFAT) gene expression and activity in patients with type 2 diabetes: inter-relationships with hyperglycaemia and oxidative stress. Clin Biochem 40, 952-957

12. Zhang, H., Jia, Y., Cooper, J. J., Hale, T., Zhang, Z., and Elbein, S. C. (2004) Common variants in glutamine:fructose-6-phosphate amidotransferase 2 (GFPT2) gene are associated with type 2 diabetes, diabetic nephropathy, and increased GFPT2 mRNA levels. J Clin Endocrinol Metab 89, 748-755

13. Qian, Y., Ahmad, M., Chen, S., Gillespie, P., Le, N., Mennona, F., Mischke, S., So, S. S., Wang, H., Burghardt, C., Tannu, S., Conde-Knape, K., Kochan, J., and Bolin, D. (2011) Discovery of 1arylcarbonyl-6,7-dimethoxyisoquinoline derivatives as glutamine fructose-6-phosphate amidotransferase (GFAT) inhibitors. Bioorg Med Chem Lett 21, 6264-6269

14. Dong, T., Kang, X., Liu, Z., Zhao, S., Ma, W., Xuan, Q., Liu, H., Wang, Z., and Zhang, Q. (2016) Altered glycometabolism affects both clinical features and prognosis of triple-negative and neoadjuvant chemotherapy-treated breast cancer. Tumour Biol 37, 8159-8168

15. Ren, S., Shao, Y., Zhao, X., Hong, C. S., Wang, F., Lu, X., Li, J., Ye, G., Yan, M., Zhuang, Z., Xu, C., $\mathrm{Xu}, \mathrm{G}$., and Sun, Y. (2016) Integration of Metabolomics and Transcriptomics Reveals Major Metabolic Pathways and Potential Biomarker Involved in Prostate Cancer. Mol Cell Proteomics 15, 154-163

16. Li, L. L., Shao, M. M., Peng, P. K., Yang, C. T., Song, S. S., Duan, F. F., Jia, D. W., Zhang, M. M., Zhao, J. J., Zhao, R., Wu, W. C., Wang, L., Li, C., Wu, H., Zhang, J., Wu, X., Ruan, Y. Y., and Gu, J. X. (2017) High expression of GFAT1 predicts unfavorable prognosis in patients with hepatocellular carcinoma. Oncotarget 8, 19205-19217

17. Guillaumond, F., Leca, J., Olivares, O., Lavaut, M. N., Vidal, N., Berthezene, P., Dusetti, N. J., Loncle, C., Calvo, E., Turrini, O., lovanna, J. L., Tomasini, R., and Vasseur, S. (2013) Strengthened glycolysis under hypoxia supports tumor symbiosis and hexosamine biosynthesis in pancreatic adenocarcinoma. Proc Natl Acad Sci U S A 110, 3919-3924

18. Vasconcelos-dos-Santos, A., Loponte, H., Mantuano, N. R., Oliveira, I. A., de Paula, I. F., Teixeira, L. K., de-Freitas, J. C. M., Gondim, K. C., Heise, N., Mohana-Borges, R., Morgado-Diaz, J. A., Dias, W. B., and Todeschini, A. R. (2017) Hyperglycemia exacerbates colon cancer malignancy through hexosamine biosynthetic pathway. Oncogenesis 6, 13

19. Isupov, M. N., Obmolova, G., Butterworth, S., Badet-Denisot, M. A., Badet, B., Polikarpov, I., Littlechild, J. A., and Teplyakov, A. (1996) Substrate binding is required for assembly of the active conformation of the catalytic site in Ntn amidotransferases: evidence from the $1.8 \mathrm{~A}$ crystal structure of the glutaminase domain of glucosamine 6-phosphate synthase. Structure 4, 801-810 
20. Broschat, K. O., Gorka, C., Page, J. D., Martin-Berger, C. L., Davies, M. S., Huang Hc, H. C., Gulve, E. A., Salsgiver, W. J., and Kasten, T. P. (2002) Kinetic characterization of human glutaminefructose-6-phosphate amidotransferase I: potent feedback inhibition by glucosamine 6phosphate. J Biol Chem 277, 14764-14770

21. Richez, C., Boetzel, J., Floquet, N., Koteshwar, K., Stevens, J., Badet, B., and Badet-Denisot, M. A. (2007) Expression and purification of active human internal His(6)-tagged L-glutamine: DFructose-6P amidotransferase I. Protein Expr Purif 54, 45-53

22. Ruegenberg, S., Horn, M., Pichlo, C., Allmeroth, K., Baumann, U., and Denzel, M. S. (2020) Loss of GFAT-1 feedback regulation activates the hexosamine pathway that modulates protein homeostasis. Nat. Commun. 11, 16

23. Huynh, Q. K., Gulve, E. A., and Dian, T. (2000) Purification and characterization of glutamine:fructose 6-phosphate amidotransferase from rat liver. Arch Biochem Biophys 379, 307-313

24. Hu, Y., Riesland, L., Paterson, A. J., and Kudlow, J. E. (2004) Phosphorylation of mouse glutamine-fructose-6-phosphate amidotransferase 2 (GFAT2) by cAMP-dependent protein kinase increases the enzyme activity. J Biol Chem 279, 29988-29993

25. Dai, W. W., Dierschke, S. K., Toro, A. L., and Dennis, M. D. (2018) Consumption of a high fat diet promotes protein O-GlcNAcylation in mouse retina via NR4A1-dependent GFAT2 expression. Biochim. Biophys. Acta-Mol. Basis Dis. 1864, 3568-3576

26. Elson, L. A., and Morgan, W. T. (1933) A colorimetric method for the determination of glucosamine and chondrosamine. Biochem J 27, 1824-1828

27. de Queiroz, R. M., Oliveira, I. A., Piva, B., Catao, F. B., Rodrigues, B. D., Pascoal, A. D., Diaz, B. L., Todeschini, A. R., Caarls, M. B., and Dias, W. B. (2019) Hexosamine Biosynthetic Pathway and Glycosylation Regulate Cell Migration in Melanoma Cells. Front. Oncol. 9, 14

28. Durand, P., Golinelli-Pimpaneau, B., Mouilleron, S., Badet, B., and Badet-Denisot, M. A. (2008) Highlights of glucosamine-6P synthase catalysis. Arch Biochem Biophys 474, 302-317

29. Krȩżel, A., Leśniak, W., Jeżowska-Bojczuk, M., Młynarz, P., Brasuñ, J., Kozłowski, H., and Bal, W. (2001) Coordination of heavy metals by dithiothreitol, a commonly used thiol group protectant. Journal of Inorganic Biochemistry 84, 77-88

30. Mouilleron, S., Badet-Denisot, M. A., Pecqueur, L., Madiona, K., Assrir, N., Badet, B., and Golinelli-Pimpaneau, B. (2012) Structural basis for morpheein-type allosteric regulation of Escherichia coli glucosamine-6-phosphate synthase: equilibrium between inactive hexamer and active dimer. J Biol Chem 287, 34533-34546

31. Olchowy, J., Gabriel, I., and Milewski, S. (2007) Functional domains and interdomain communication in Candida albicans glucosamine-6-phosphate synthase. Biochem J 404, 121 130

32. Leriche, C., BadetDenisot, M. A., and Badet, B. (1996) Characterization of a phosphoglucose isomerase-like activity associated with the carboxy-terminal domain of Escherichia coli glucosamine-6-phosphate synthase. J. Am. Chem. Soc. 118, 1797-1798

33. Floquet, N., Mouilleron, S., Daher, R., Maigret, B., Badet, B., and Badet-Denisot, M. A. (2007) Ammonia channeling in bacterial glucosamine-6-phosphate synthase (GIms): molecular dynamics simulations and kinetic studies of protein mutants. FEBS Lett 581, 2981-2987

34. Mouilleron, S., Badet-Denisot, M. A., Badet, B., and Golinelli-Pimpaneau, B. (2011) Dynamics of glucosamine-6-phosphate synthase catalysis. Arch Biochem Biophys 505, 1-12

35. Mouilleron, S., Badet-Denisot, M. A., and Golinelli-Pimpaneau, B. (2006) Glutamine binding opens the ammonia channel and activates glucosamine-6P synthase. J Biol Chem 281, 44044412 
36. Nakaishi, Y., Bando, M., Shimizu, H., Watanabe, K., Goto, F., Tsuge, H., Kondo, K., and Komatsu, M. (2009) Structural analysis of human glutamine:fructose-6-phosphate amidotransferase, a key regulator in type 2 diabetes. FEBS Lett 583, 163-167

37. Floquet, N., Durand, P., Maigret, B., Badet, B., Badet-Denisot, M. A., and Perahia, D. (2009) Collective motions in glucosamine-6-phosphate synthase: influence of ligand binding and role in ammonia channelling and opening of the fructose-6-phosphate binding site. J Mol Biol 385, 653-664

38. Gabriel, I., Olchowy, J., Stanislawska-Sachadyn, A., Mio, T., Kur, J., and Milewski, S. (2004) Phosphorylation of glucosamine-6-phosphate synthase is important but not essential for germination and mycelial growth of Candida albicans. FEMS Microbiol Lett 235, 73-80

39. Graack, H. R., Cinque, U., and Kress, H. (2001) Functional regulation of glutamine:fructose-6phosphate aminotransferase 1 (GFAT1) of Drosophila melanogaster in a UDP-Nacetylglucosamine and cAMP-dependent manner. Biochem J 360, 401-412

40. Zhou, J., Huynh, Q. K., Hoffman, R. T., Crook, E. D., Daniels, M. C., Gulve, E. A., and McClain, D. A. (1998) Regulation of glutamine:fructose-6-phosphate amidotransferase by cAMPdependent protein kinase. Diabetes 47, 1836-1840

41. Chang, Q., Su, K., Baker, J. R., Yang, X., Paterson, A. J., and Kudlow, J. E. (2000) Phosphorylation of human glutamine:fructose-6-phosphate amidotransferase by cAMP-dependent protein kinase at serine 205 blocks the enzyme activity. J Biol Chem 275, 21981-21987

42. Eguchi, S., Oshiro, N., Miyamoto, T., Yoshino, K., Okamoto, S., Ono, T., Kikkawa, U., and Yonezawa, K. (2009) AMP-activated protein kinase phosphorylates glutamine : fructose-6phosphate amidotransferase 1 at Ser243 to modulate its enzymatic activity. Genes Cells 14, 179-189

43. Zibrova, D., Vandermoere, F., Goransson, O., Peggie, M., Marino, K. V., Knierim, A., Spengler, K., Weigert, C., Viollet, B., Morrice, N. A., Sakamoto, K., and Heller, R. (2017) GFAT1 phosphorylation by AMPK promotes VEGF-induced angiogenesis. Biochem J 474, 983-1001

44. Wang, Z. V., Deng, Y. F., Gao, N. G., Pedrozo, Z., Li, D. L., Morales, C. R., Criollo, A., Luo, X., Tan, W., Jiang, N., Lehrman, M. A., Rothermel, B. A., Lee, A. H., Lavandero, S., Mammen, P. P. A., Ferdous, A., Gillette, T. G., Scherer, P. E., and Hill, J. A. (2014) Spliced X-Box Binding Protein 1 Couples the Unfolded Protein Response to Hexosamine Biosynthetic Pathway. Cell 156, 11791192

45. Liu, B., Huang, Z. B., Chen, X., See, Y. X., Chen, Z. K., and Yao, H. K. (2019) Mammalian Target of Rapamycin 2 (MTOR2) and C-MYC Modulate Glucosamine-6-Phosphate Synthesis in Glioblastoma (GBM) Cells Through Glutamine: Fructose-6-Phosphate Aminotransferase 1 (GFAT1). Cell. Mol. Neurobiol. 39, 415-434

46. Moloughney, J. G., Kim, P. K., Vega-Cotto, N. M., Wu, C. C., Zhang, S. S., Adlam, M., Lynch, T., Chou, P. C., Rabinowitz, J. D., Werlen, G., and Jacinto, E. (2016) mTORC2 Responds to Glutamine Catabolite Levels to Modulate the Hexosamine Biosynthesis Enzyme GFAT1. Mol. Cell 63, 811-826

47. Ye, F., Maegawa, H., Morino, K., Kashiwagi, A., Kikkawa, R., Xie, M., and Shen, Z. (2004) A simple and sensitive method for glutamine:fructose-6-phosphate amidotransferase assay. $J$ Biochem Biophys Methods 59, 201-208

48. Andrade, M. A., Chacon, P., Merelo, J. J., and Moran, F. (1993) Evaluation of secondary structure of proteins from UV circular dichroism spectra using an unsupervised learning neural network. Protein Eng 6, 383-390

49. Sreerama, N., Venyaminov, S. Y., and Woody, R. W. (1999) Estimation of the number of alphahelical and beta-strand segments in proteins using circular dichroism spectroscopy. Protein Sci 8, 370-380 
50. Sreerama, N., and Woody, R. W. (1993) A self-consistent method for the analysis of protein secondary structure from circular dichroism. Anal Biochem 209, 32-44

51. Whitmore, L., and Wallace, B. A. (2004) DICHROWEB, an online server for protein secondary structure analyses from circular dichroism spectroscopic data. Nucleic Acids Res 32, W668-673

52. Whitmore, L., and Wallace, B. A. (2008) Protein secondary structure analyses from circular dichroism spectroscopy: methods and reference databases. Biopolymers 89, 392-400

53. Sievers, F., Wilm, A., Dineen, D., Gibson, T. J., Karplus, K., Li, W., Lopez, R., McWilliam, H., Remmert, M., Soding, J., Thompson, J. D., and Higgins, D. G. (2011) Fast, scalable generation of high-quality protein multiple sequence alignments using Clustal Omega. Mol Syst Biol 7, 539

54. Roy, A., Kucukural, A., and Zhang, Y. (2010) I-TASSER: a unified platform for automated protein structure and function prediction. Nat Protoc 5, 725-738

55. Case, D. A., Babin, V., Berryman, J. T., Betz, R. M., Cai, Q., Cerutti, D. S., Cheatham III, T. E., Darden, T. A., Duke, R. E., Gohlke, H., Goetz, A. W., Gusarov, S., Homeyer, N., Janowski, P., Kaus, J., Kolossváry, I., Kovalenko, A., Lee, T. S., LeGrand, S., Lunchko, T., Luo, R., Madej, B., Merz, K. M., Paesani, F., Roe, D. R., Roitberg, A., Sagui, C., Salomon-Ferrer, R., Seabra, G., Simmerling, C. L., Smith, W., Swails, J., Walker, R. C., Wang, J., Wolf, R. M., Wu, X., and Kollman, P. A. (2014) AMBER 14, University of California, San Francisco

56. Maier, J. A., Martinez, C., Kasavajhala, K., Wickstrom, L., Hauser, K. E., and Simmerling, C. (2015) ff14SB: Improving the Accuracy of Protein Side Chain and Backbone Parameters from ff99SB. J Chem Theory Comput 11, 3696-3713

57. Jorgensen, W. L., Chandrasekhar, J., Madura, J. D., Impey, R. W., and Klein, M. L. (1983) Comparison of simple potential functions for simulating liquid water J. Chem. Phys. 79, 926935

58. Li, H., Robertson, A. D., and Jensen, J. H. (2005) Very fast empirical prediction and rationalization of protein pKa values. Proteins $61,704-721$

59. Ryckaert, J. P., Ciccotti, G., and Berendsen, H. J. C. (1977) Numerical integration of the cartesian equations of motion of a system with constraints: molecular dynamics of $n$-alkanes. Journal of Computational Physics 23, 327-341

60. Essmann, U., Perera, L., Berkowitz, M. L., Darden, T., Lee, H., and Pedersen, L. G. (1995) A smooth particle mesh Ewald method. J. Chem. Phys. 103, 8577-8593

61. Schneider, T., and Stoll, E. (1978) Molecular-dynamics study of a three-dimensional onecomponent model for distortive phase transitions. Phys. Rev. B 17, 1302-1322

62. Berendsen, H. J. C., Postma, J. P. M., vangunsteren, W. F., Dinola, A., and Haak, J. R. (1984) Molecular dynamics with coupling to an external bath. J Chem Phys 81, 3684-3690

63. Humphrey, W., Dalke, A., and Schulten, K. (1996) VMD: Visual molecular dynamics. J. Mol. Graph. 14, 33-38 
Table1. Purification of rhGFAT2s in E. coli

\begin{tabular}{llll}
\hline Purified protein & Specific activitya $\mathbf{~ ( U / m g ) ~}$ & Yield $^{b}$ (mg GFAT/L growth culture) & Purity (\%) \\
\hline rhGFAT2-his & $2.66 \times 10^{-4}$ & 13.42 & $96.6 \%$ \\
rhGFAT2 w/o tag & $2.83 \times 10^{-4}$ & 1.69 & $96.3 \%$ \\
\hline
\end{tabular}

a Enzyme units activity are defined as the Specific activity was expressed as units ( $\mu \mathrm{mol}$ of GlcN-6P synthesized per min at $37^{\circ} \mathrm{C}$ ) per $\mathrm{mg}$ of protein.

b Protein concentrations were determined by the method of Bradford using bovine serum albumin as standards.

Table 2. Kinetic parameters of reations catalysed by rhGFAT2-his

\begin{tabular}{lllll}
\hline Type of activity & Substrate $(\mathbf{s})$ & $\boldsymbol{K}_{m}(\mathrm{Gln})(\mathrm{mM})$ & $\boldsymbol{K}_{m}$ (Fru-6P) (mM) & $\boldsymbol{K}_{\text {cat }}\left(\mathbf{m i n}^{-1}\right)$ \\
\hline $\begin{array}{l}\text { Aminohydrolysing } \\
\text { activity }\end{array}$ & w/o Fru-6P & $0.820 \pm 0.335$ & - & $0.021 \pm 0.003$ \\
& w/ Fru-6P & $1.814 \pm 1.158$ & - & $0.079 \pm 0.016$ \\
\hline Isomerase activity & w/o Gln & - & $0.711 \pm 0.170$ & $0.322 \pm 0.022$ \\
\hline \multirow{2}{*}{ GlcN-6P synthetic activity } & $\boldsymbol{4}$ Fru-6P & - & $0.957 \pm 0.502^{*}$ & $0.032 \pm 0.007^{*}$ \\
& $\boldsymbol{\Lambda}$ Gln & $0.763 \pm 0.332^{*}$ & - & $0.040 \pm 0.008^{*}$ \\
\hline
\end{tabular}

* The kinetic parameters for synthase activity were generated through Michaelis-Menten fitting, therefore must be considered as apparent values.

Table 3. Secondary structure composition of rhGFAT2, based on experimental and theoretical data.

\begin{tabular}{lccc}
\hline Method & $\boldsymbol{\alpha}-\mathrm{Helix}$ & $\boldsymbol{\beta}$-Sheet & Random \\
\hline Circular Dichroism $^{\mathrm{a}}$ & $33 \%$ & $18 \%$ & $49 \%$ \\
\hline Molecular Dynamics $^{\mathrm{b}}$ & $36 \%$ & $19 \%$ & $45 \%$ \\
\hline a The secondary structure content of rhGFAT2-his was estimated \\
from circular dichroism data, using different algorithms available on \\
the Dichroweb server. \\
b The average secondary structure of GFAT2 from molecular \\
dynamics simulation time was shown.
\end{tabular}

Figures 


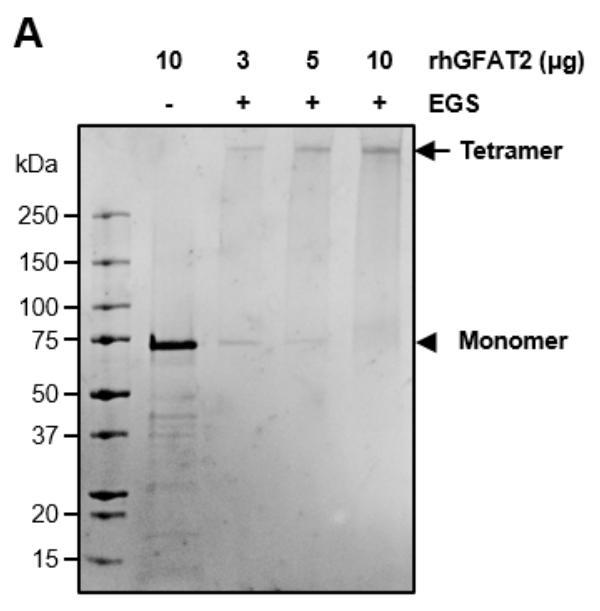

B
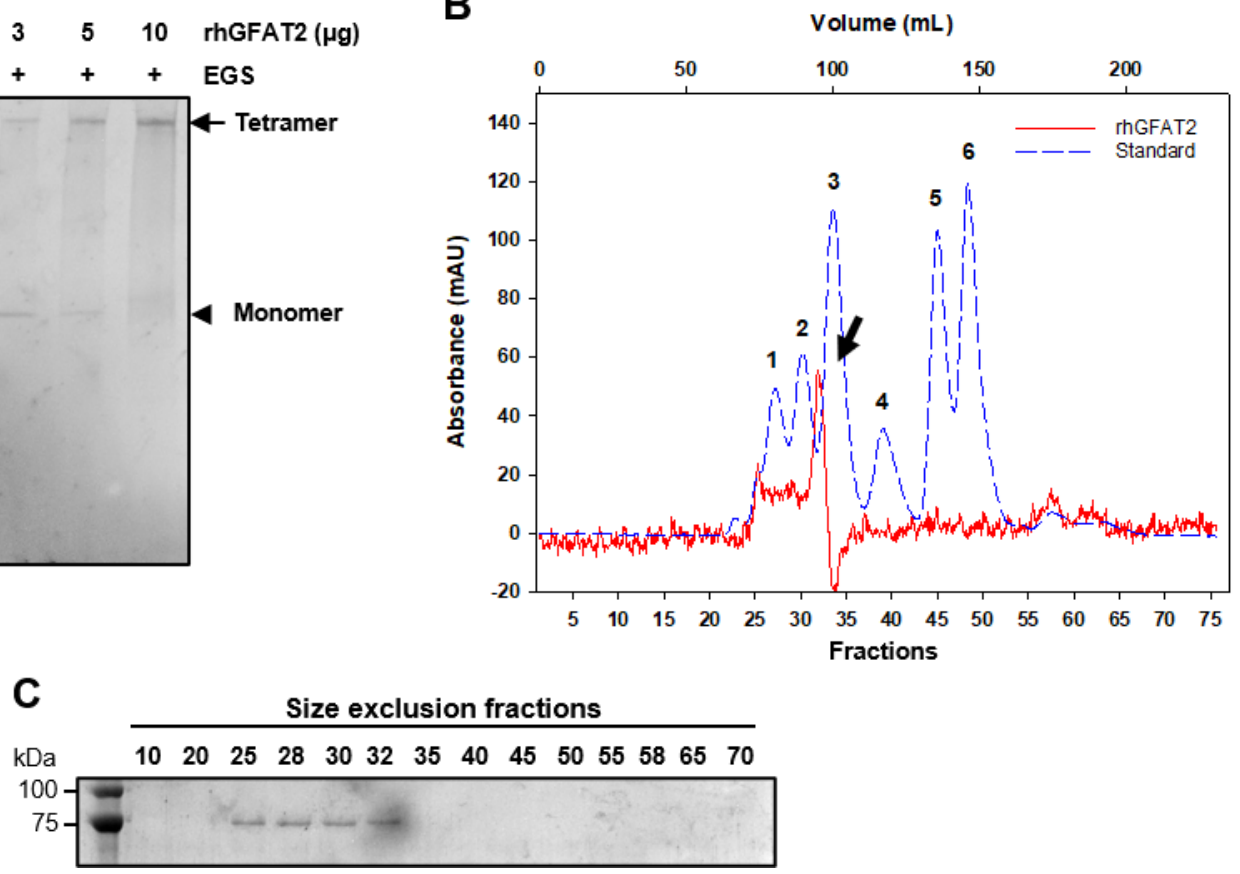

Fig. 1 - Evaluation of the rhGFAT2 oligomeric state. (A) Cross-linking assay in which 3, 5, or 10 $\mu \mathrm{g}$ of hGFAT2-his were incubated in the presence of $1 \mathrm{mM}$ EGS. The control was performed by incubation of $10 \mu \mathrm{g}$ of rhGFAT2-his in the absence of EGS. Arrow and arrowhead represent the tetramer and monomer, respectively. (B) Size exclusion chromatogram of rhGFAT2-his (solid red line) in Superdex 200 16/200 column. The arrow represents the major peak of the enzyme. Standard proteins (dashed blue line) were subjected to the same condition as rhGFAT2 and are described as follows: 1Thyroglobulin (669 kDa), 2- Apoferritin (443 kDa), 3- $\beta$-amylase (200 kDa), 4- BSA (66 kDa), 5Carbon anhydrase $(29 \mathrm{kDa})$ and 6- Cytochrome c oxidase $(12.4 \mathrm{kDa})$. The collected fractions were subjected to SDS-PAGE followed by Coomassie blue staining (C). 
A

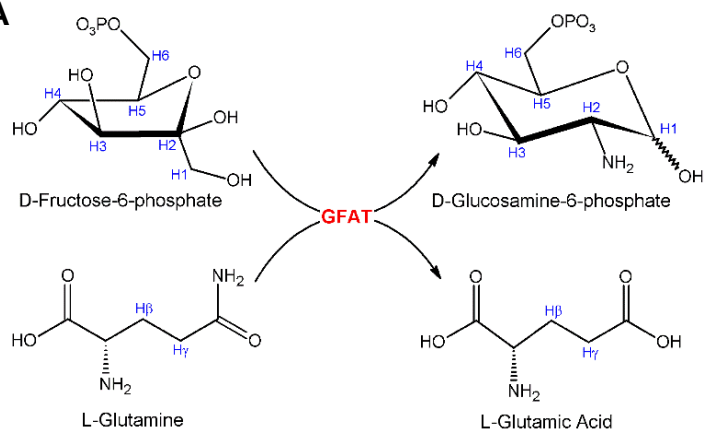

C
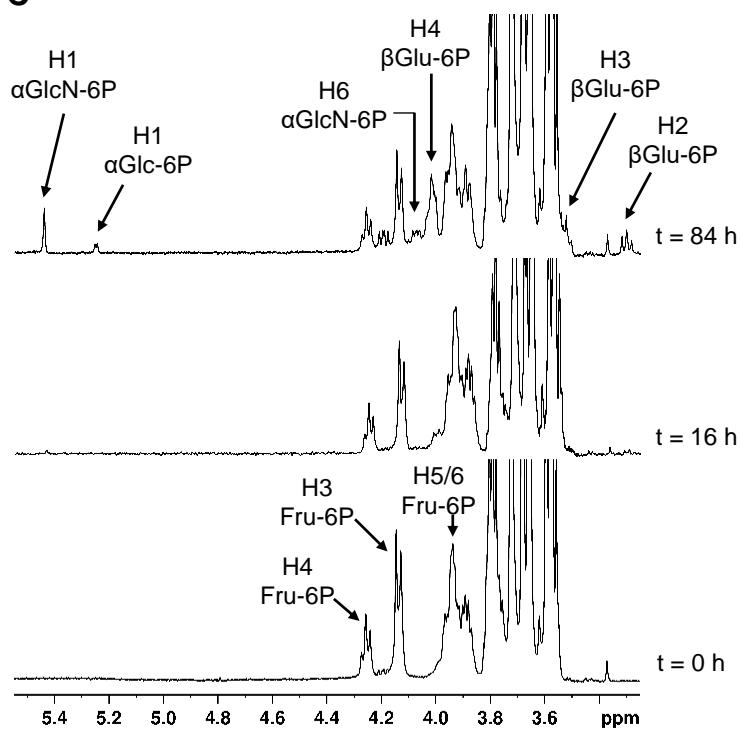

B

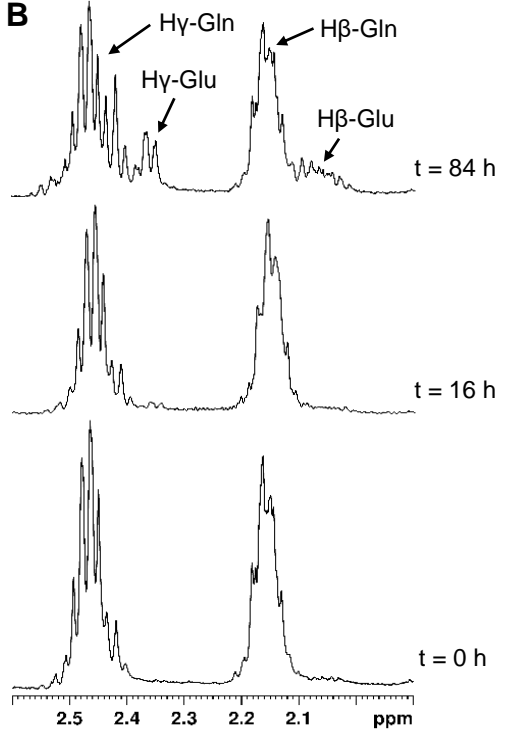

D

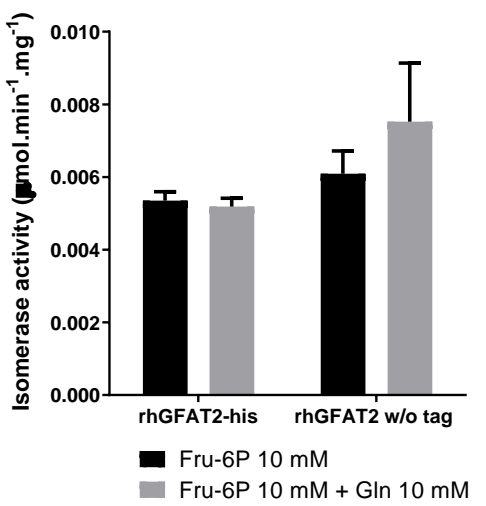

E

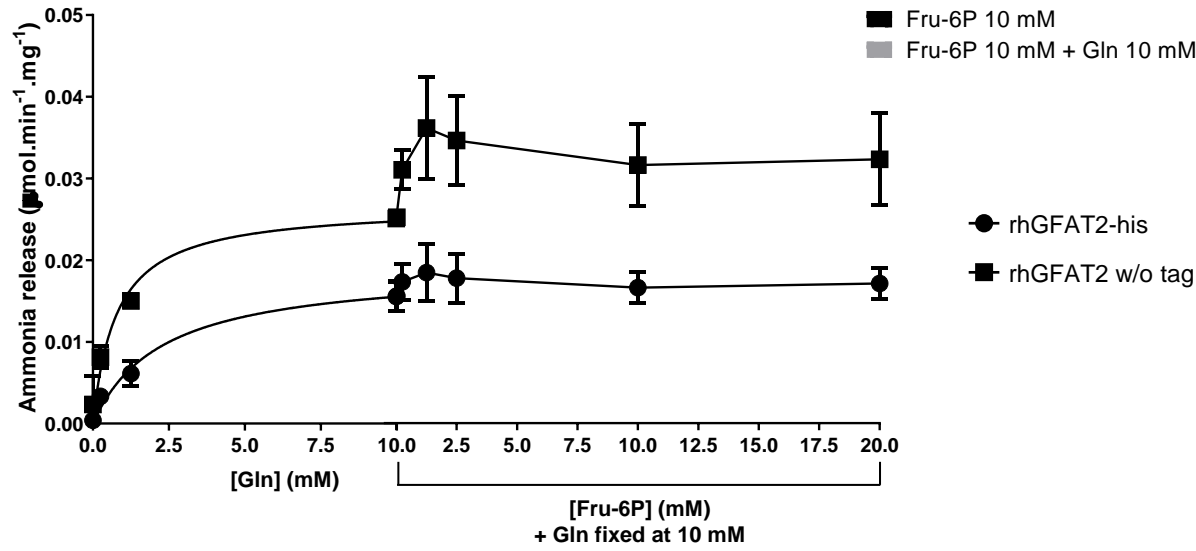

Fig. 2 - Exploring PGI-like activity of rhGFAT2. (A) Reaction scheme of complete GFAT reaction. (B and C) Time course of rhGFAT2-his reaction in presence of Gln and Fru-6P (both at $3 \mathrm{mM}$ ) in 50 $\mathrm{mM}$ deuterated phosphate buffer $\mathrm{pH} 7.4$ with $1 \mathrm{mM}$ DTT at $25^{\circ} \mathrm{C}$, monitored by ${ }^{1} \mathrm{H}$ NMR spectroscopy. The times at which spectral data were acquired refer to the addition of rhGFAT2-his $(100 \mu \mathrm{g})$ as $\mathrm{t}=0$ h. (B) Region of ${ }^{1} \mathrm{H}$ NMR spectra detailing Gln and Glu peaks. (C) Region of ${ }^{1} \mathrm{H}$ NMR spectra detailing Fru-6P, Glc-6P and GlcN-6P peaks. (D) Isomerization of Fru-6P in Glc-6P catalyzed by rhGFAT2-his or rhGFAT2 without (w/o) HisTag assessed either in absence (black bars) or in presence (gray bars) of Gln. (E) Ammonia release from Gln, catalyzed by rhGFAT2-his (black circles) and rhGFAT2 without (w/o) HisTag (black squares). The enzyme was incubated with increasing amounts of Gln until $10 \mathrm{mM}$, and with fixed Gln at $10 \mathrm{mM}$ and variable concentrations of Fru-6P as indicated. 
bioRxiv preprint doi: https://doi.org/10.1101/2020.07.13.201285; this version posted July 14, 2020. The copyright holder for this preprint (which was not certified by peer review) is the author/funder, who has granted bioRxiv a license to display the preprint in perpetuity. It is made available under aCC-BY-NC-ND 4.0 International license.

A

E. coli Glms
C. albicans GFA
H. sapiens GFAT1
H. sapiens GFAT2

E. coli Glms

C. albicans GFA

H. sapiens GFAT1

H. sapiens GFAT2
E. coli GlmS
C. albicans GFA
H. sapiens GFAT1
H. sapiens GFAT2

146 RAIPQLRGAYGTVIMDSRHPDTLLAARSGSPLVIGLGMG--------------------- 186

180 QVLHELEGSYGLLVKSYHYPGEVCGTRKGSPLLVGVKTDKKLKVDFVDVEFEAQQQHRPQ 239

176 RVIQQLEGAFALVFKSVHFPGQAVGTRRGSPLLIGVRSEHKLSTDHIPILYRTGKDK--K 233

173 RVIQQLEGAFALVFKSVHYPGEAVATRRGSPLLIGVRSKYKLSTEQIPILYRTCTLENVK 232 : : : ${ }^{\star}{ }^{\star}:$ : . : . . : .*. . :*****: :*:

\section{$\mathbf{B}$}

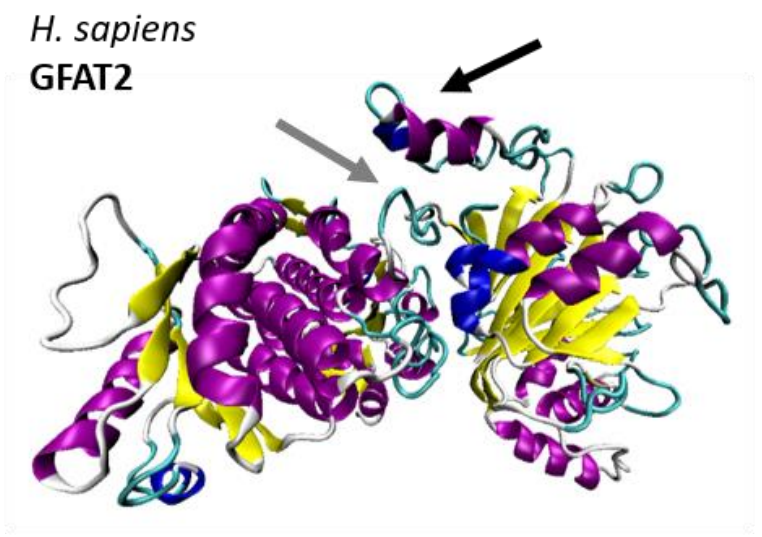

\section{C. albicans}

GFA

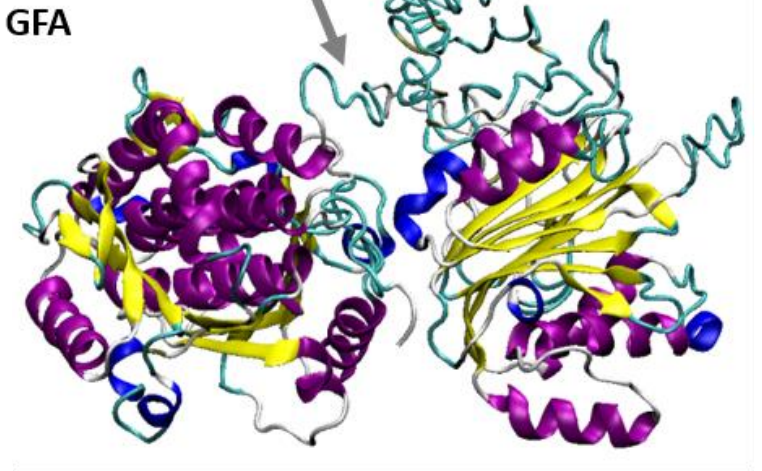

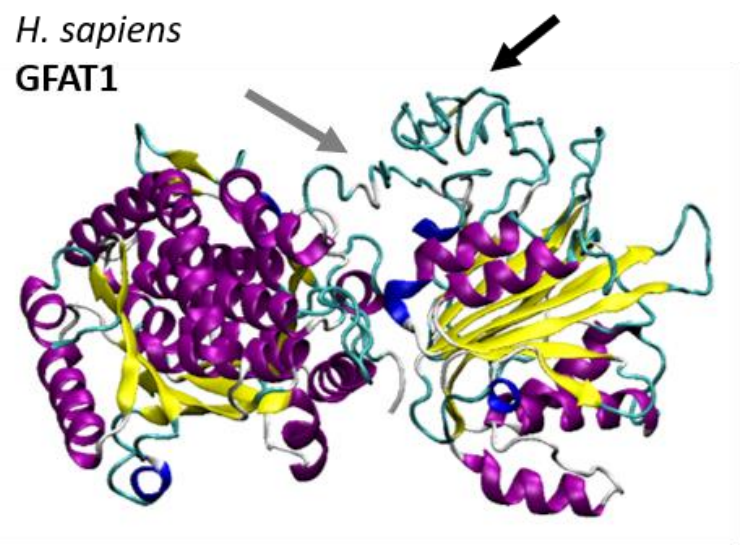

RRFIFLEEGDIAEITRRSVNIFDKT----GAEVKRQDIESNLQYDAGDKGIYRHYMQKEI 257 KKVLFLEDDDIAHIYDGELRIHRASTKSAGESTVRPIQTLEMELNEIMKGPYKHFMQKEI 359 NRVIFLEDDDVAAVVDGRLSIHRIK-RTAGDHPGRAVQTLQMELQQIMKGNFSSFMQKEI 329 NRVIFLEDDDIAAVADGKLSIHRVK-RSASDDPSRAIQTLQMELQQIMKGNFSAFMQKEI 330 -SCNLSRVDSTTCL-FPVEEKAVEYYFASDA.SAVIEHT 270 EFFFASDASAIIEHT 271 
A
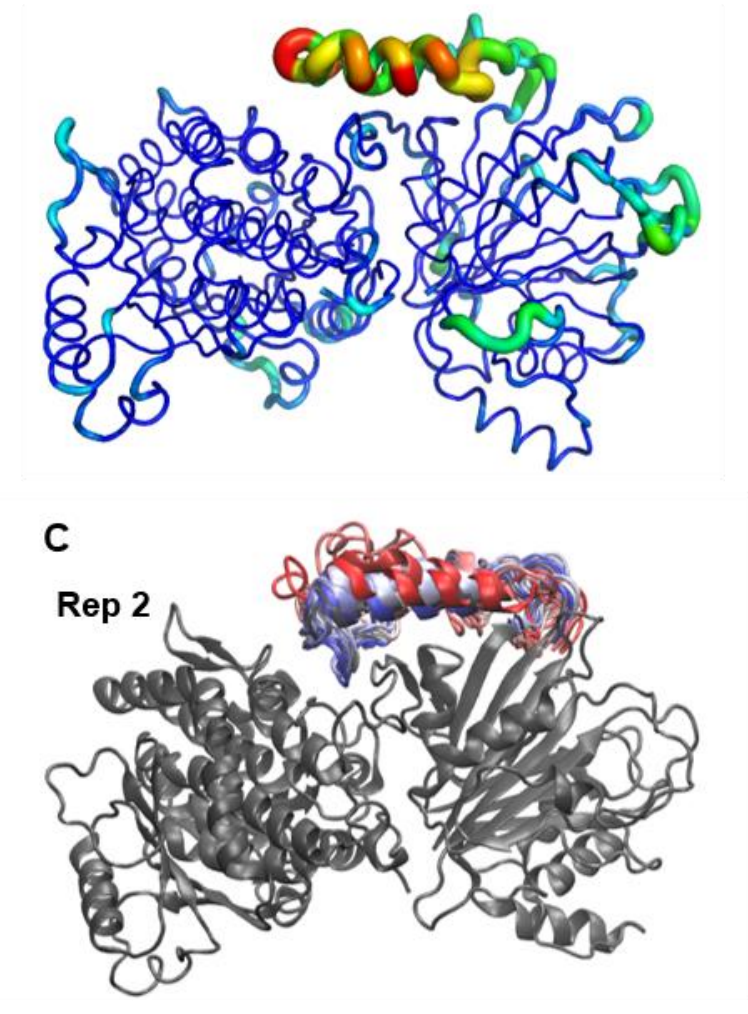

B
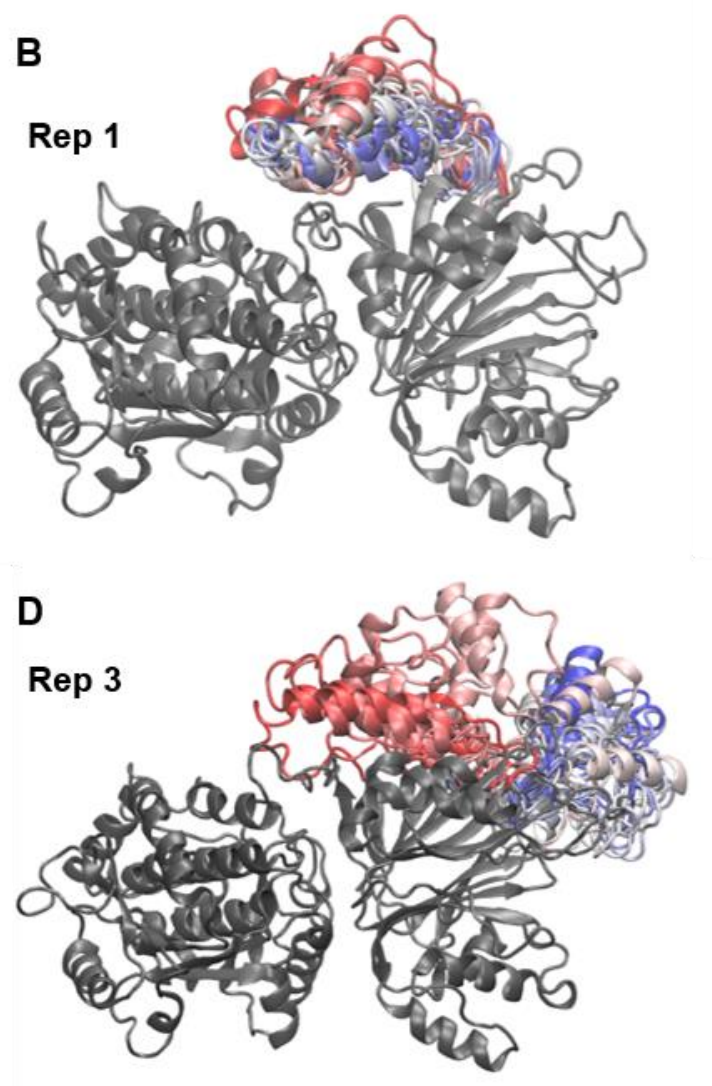

Fig. 4 - Loop stability. (A) Three-dimensional root mean square fluctuation (RMSF) of protein residues during $\mathrm{MD}$ simulation of replica 1 . The protein is shown in tubes, whose thickness and color reflects the extent of each residue fluctuation (0.8 to $7.4 \AA$ A ). (B-D) Final frames from MD simulation replicas, with the protein represented in cartoon and colored in gray. The loop conformation is shown throughout simulation time and colored accordingly: initial frames are colored in red, intermediates in white and final frames in blue. 

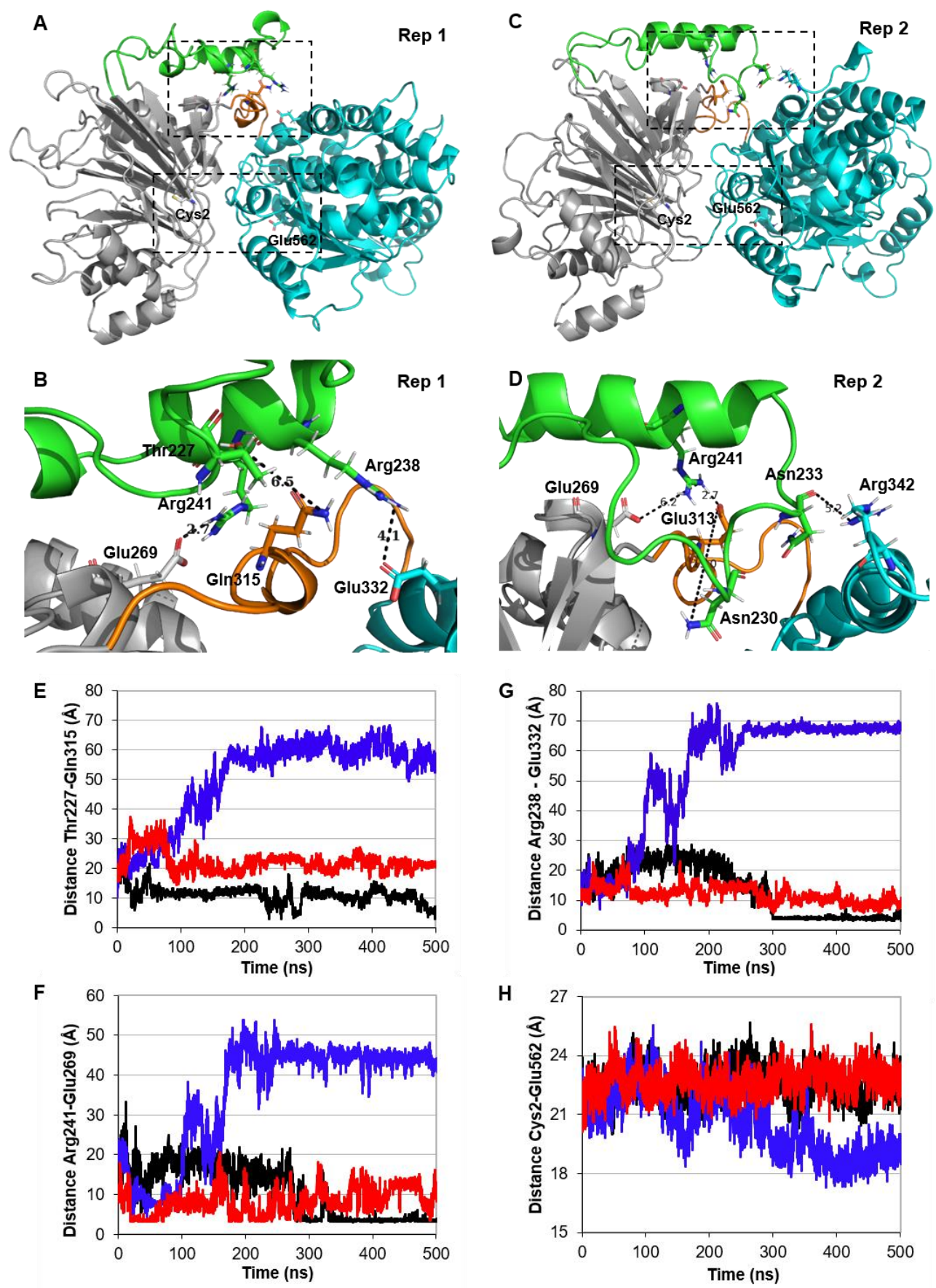

Fig. 5 - Structural features of rhGFAT2. (A-D) Views of rhGFAT2 from the most populated cluster from MD simulations of replicas 1 and 2, depicting the full protein structure (A and C) and closer views of the loop region (B and $\mathrm{D}$ ). The protein structure is represented in cartoon and its regions are colored as follows: the GLN domain in gray, the loop in green, the ISOM domain in cyan and the interdomain region in orange. Key residues monitored in distance analysis are represented as sticks and the distances are represented by dashed black traces. (E-G) Analysis of the distances between the residues Thr227 and Gln315 (E), Glu269 and Arg241 (F), and Arg238 and Glu332 (G), reflecting the interaction of the loop with the interdomain region, the GLN domain, and ISOM domain, respectively, throughout simulation time. (H) Distance between catalytic residues from GLN domain (Cys2) and ISOM domain (Glu562) during MD simulation time. Black lines represent the data from replica 1, red lines from replica 2 , and blue lines from replica 3 . 

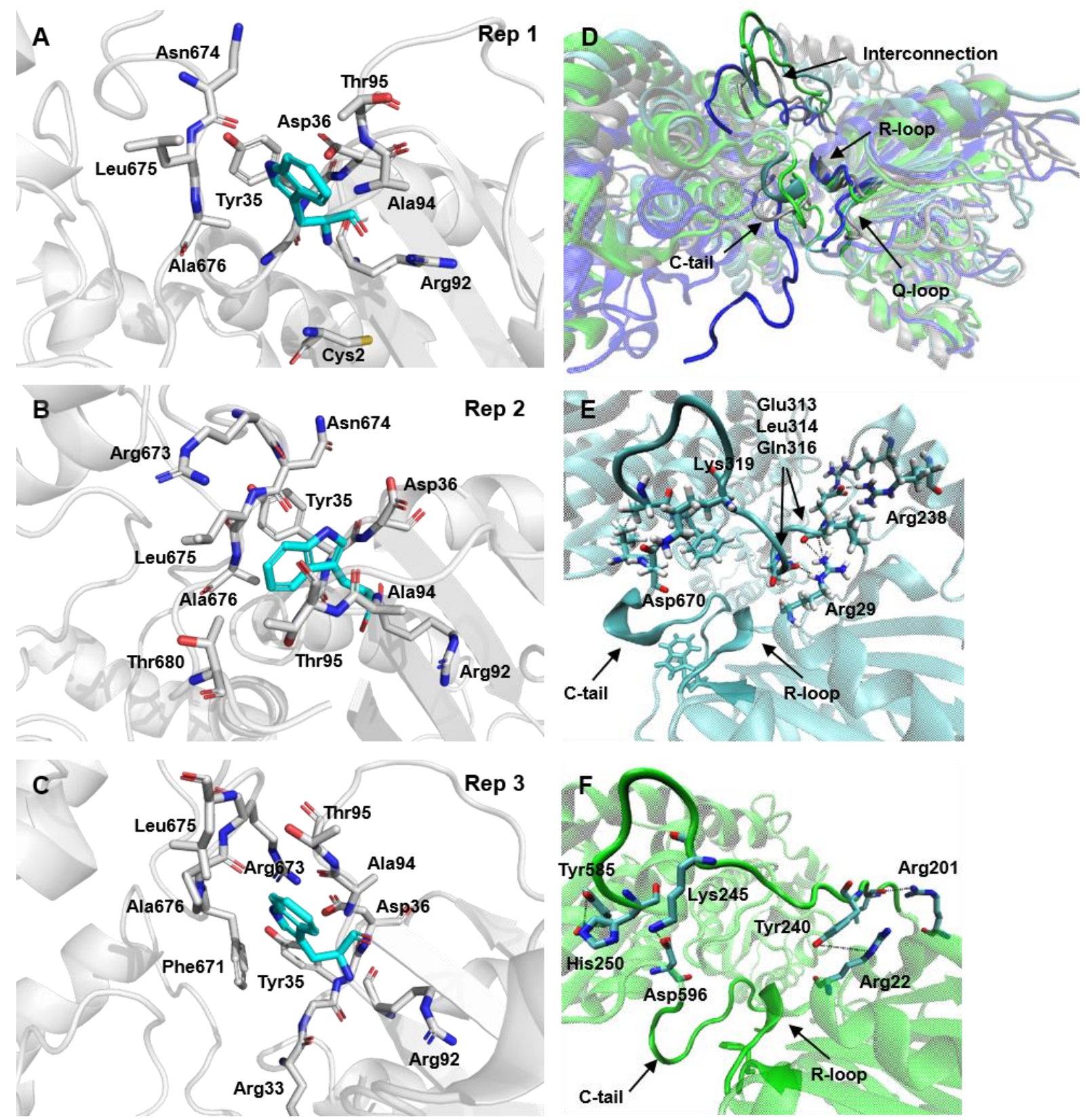

Fig. 6 - Tryptophan neighborhood in hGFAT2 and GImS. (A-C) Closer view of the residues that are 4 angstroms from Trp93 on the most populated cluster from MD simulations of replicas 1 (A), 2 (B), and 3 (C). The residues in contact to Trp93 are represented in sticks and colored in gray; Trp93 is also in sticks but colored in cyan (the hydrogens were removed for clarity). The protein backbone is represented in cartoon and colored in gray. (D) Views of the most populated cluster from MD simulations of replicas 1 (gray), 2 (blue), 3 (cyan), aligned to GlmS structure (green, PDB ID: 2J6H). The proteins were aligned by GLN domain and are represented in cartoon; the interdomain region, Ctail and Q- and R-loops are highlighted and indicated. (E, F) Closer view of the interdomain region in replica 2 of hGFAT2 DM (E) and GlmS (F), depicting the interactions between this region and the overall protein. The residues involved in those interactions are represented in sticks and colored in cyan, and the distances are represented by dashed black traces. 